\title{
Ações Afirmativas no Ensino Superior: revisão quantitativa e qualitativa de literatura ${ }^{1}$
}

\section{Affirmative Actions in Post Secondary Education: Quantitative and Qualitative Literature Review² \\ Acciones Afirmativas en la enseñanza superior: Revisión cuantitativa y cualitativa de la producción bibliográfica ${ }^{3}$}

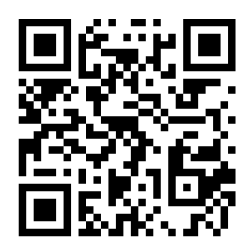

Recibido • Received • Recebido: 05 / 04 / 2018

Corregido • Revised • Revisado: 03 / 09 / 2019

Aceptado • Accepted • Aprovado: 28 / 11 / 2019

\footnotetext{
${ }^{1}$ Temos clareza da ambiguidade do termo ensino superior utilizado em diferentes realidades. Preferimos utiliza-lo ao invés do termo genérico universidade por entender que o primeiro refere-se ao processo de educação que se estabelece nas instituições universidades.

${ }^{2}$ We are clear about the ambiguity of the term higher education used in different realities. We prefer to use it instead of the generic term university because we understand that the former refers to the process of education established in university institutions.

${ }^{3}$ Tenemos claridad sobre la ambigüedad del término enseñanza superior al usarlo en diferentes contextos. Preferimos utilizarlo en vez del término genérico universidad, entendiendo que el primero hace referencia al proceso de educación en las instituciones universitarias.
} 
doi: http://doi.org/10.15359/ree.24-1.16

URL: http://www.una.ac.cr/educare

CORREO: educare@una.cr

Resumo: As ações afirmativas são mecanismos de inclusão social, que mobilizam várias esferas da sociedade. Este artigo examina a produção científica de acesso gratuito no Brasil (nacional einternacional) sobre ações afirmativas no ensino superior, buscando um panorama geral sobre o tema. Trata-se, portanto, de uma análise literária revisional ampla (quantitativa e qualitativa) sobre as publicações dos dez últimos anos, em três idiomas (português, inglês e espanhol), partindo de 1105 artigos, de três bases de dados (SciELO, SPELL e ANPAD), que foram triados por critérios pré-estabelecidos, resultando em 119 para leitura integral e 96 para a análise propriamente dita. A análise dos artigos foi realizada a partir de 4 categorias que examinaram: ações afirmativas em diferentes países, desempenho de alunos, contexto histórico das publicações e avaliação das políticas. A produção no tema tem aumentado ao longo dos anos, porém, com algumas fragilidades como a concentração de estudos sobre realidades muito específicas. É preciso avançar na análise da trajetória das ações afirmativas para entender melhor sua aplicação prática e propiciar diálogos mais consistentes entre as realidades investigadas.

Palavras-chaves: Ações Afirmativas; Ensino Superior; Universidade; Revisão de Literatura.

Abstract: Affirmative actions are mechanisms of social inclusion that mobilize several spheres of society. This article examines the scientific production obtained by open access bases in Brazil (national and international) of affirmative action for access to post secondary education, aiming an overview of the theme. This is therefore a broad (quantitative and qualitative) review of the publications of the last ten years, considering three languages (Portuguese, English and Spanish), starting with 1105 articles, from three databases (SciELO, SPELL and ANPAD), which were screened by pre-established criteria, resulting in 119 for integral reading and 96 for the analysis itself. The analysis of the articles was based on 4 categories which examined: affirmative actions in different countries, student performance, historical context of publications and policy evaluation. Production on the theme has increased over the years, however, with some weaknesses such as the concentration of studies on very specific realities. It is necessary to advance in the analysis of the trajectory of affirmative actions to better understand their practical application and to provide more consistent dialogues among the investigated realities.

Keywords: Affirmative Actions; Post Secondary Education; University; Literature Review.

Resumen: Las acciones afirmativas son mecanismos de inclusión social que movilizan varias esferas de la sociedad. Este artículo examina la producción científica libre de acceso en Brasil (nacional e internacional) sobre acciones afirmativas en la enseñanza superior. Busca un panorama general de lo que viene siendo publicado sobre el tema. Por lo tanto, se trata de un amplio análisis revisional (cuantitativo y cualitativo) acerca de las publicaciones cientificas de los últimos diez años, en tres idiomas (portugués, español e inglés), desde 1105 artículos en tres bases de datos (SciELO, SPELL y ANPAD), que fueron triados por criterios preestablecidos, resultando en 119 para lectura integral y 96 para el análisis propiamente dicho. El análisis de los artículos se realizó a partir de 4 categorías que examinaron: acciones afirmativas en diferentes países, desempeño de estudiantes, contexto histórico de publicaciones y evaluación de políticas. Sin embargo, la producción sobre el tema ha aumentado con los años, con algunas debilidades, como la concentración de estudios sobre realidades muy específicas. Es necesario avanzar en el análisis de la trayectoria de las acciones afirmativas para comprender mejor su aplicación práctica y proporcionar diálogos más consistentes entre las realidades investigadas.

Palabras claves: Acciones afirmativas; enseñanza superior; universidad; revisión bibliográfica. 


\section{Introdução}

As ações afirmativas são hoje parte constituinte das universidades, principalmente após a aprovação da Lei № 12.711, de 29 de agosto de 2012 (Congreso Nacional, Brasília, 2012). Porém, algumas experiências inclusivas já estavam em curso em universidades antes da entrada em vigor da lei. A Universidade Estadual do Rio de Janeiro (UERJ) foi pioneira na introdução de cotas em 2003, seguida pela Universidade Estadual do Norte Fluminense em 2004, e pela Universidade de Brasília, primeira federal a adotar reserva de vagas no mesmo ano (Kern \& Ziliotto, 2011). Segundo levantamento de janeiro de 2009, conforme e Silva \& da Silva (2012), 51 instituições no Brasil adotavam ações afirmativas, entre universidades estaduais e federais, faculdades, centros universitários e Cefets. Jaccoud \& Beghin (2002) referem que as ações afirmativas entraram no debate político durante os anos 1990. Porém, foi após a entrada em vigor da lei que cresceu o interesse por pesquisas e publicações sobre o tema, assim como para as discussões em geral, favoráveis ou contrárias às normativas.

As ações afirmativas nas universidades públicas são reservadas a estudantes em situação socioeconômica desfavorecida, negros, pardos, indígenas e pessoas com deficiência. O Brasil tem sido historicamente marcado pela falta de acesso em várias esferas da vida social. Alguns dados específicos da questão racial na educação demonstram essa afirmação, 12,7\% de negros, entre 18 e 24 anos, estão no ensino superior, comparado com 26,5\% de brancos. Nos últimos dez anos (2005-2015) computados pelo estudo do Instituto Brasileiro de Geografia e Estatística (IBGE, 2016), a democratização do ensino superior melhorou, principalmente na rede pública de ensino, com a maior participação de estratos de renda mais baixos e negros. Mesmo assim, a desigualdade de renda e de acesso educacional continuam significativas (IBGE, 2016). A diversidade não é uma característica isolada, geralmente vem associada a outra(s) condição(ões) de vulnerabilidade, fenômeno chamado de interseccionalidade, que dificulta ainda mais a inclusão de determinados grupos sociais. Por exemplo, dados demonstram que três em cada quatro pessoas em situação de pobreza são negras (IBGE, 2016).

Como o pertencimento de classe prefigura e predetermina, pelo menos em grande medida, todas as chances que os indivíduos de cada classe específica vão ter na sua vida em todas as dimensões, negar a classe equivale também a negar tudo de importante nas formas modernas de produzir injustiça e desigualdade. (Souza, 2017, p. 85)

As instituições públicas de ensino (federais, estaduais e municipais) foram responsáveis pela abertura de quase $30 \%$ de novas vagas em cursos presenciais de bacharelado entre 2009 e 2014. Essa expansão foi acompanhada do ingresso de estudantes cotistas, que no mesmo período mais do que duplicaram, passando de 5,6\% para 14\%. Porém, é sabido que o déficit educacional brasileiro necessitará de mais tempo para ser equacionado, a despeito dos melhores índices de acesso atingidos nos últimos anos (IBGE, 2016). Levanta-se, portanto, o questionamento se o 
doi: http://doi.org/10.15359/ree.24-1.16

URL: http://www.una.ac.cr/educare

CORREO: educare@una.cr

acesso à educação superior pelas ações afirmativas é o meio exclusivo para reparação dessas diferenças e se esse acesso vem ocorrendo de maneira adequada a dirimir as desigualdades.

Este artigo propõe uma revisão bibliográfica crítica, que resgata as publicações sobre ações afirmativas, no período entre janeiro de 2007 e julho de 2017. Distingue-se de outras publicações semelhantes do período, por um lado, porque busca rigor metodológico na seletividade dos materiais analisados e, por outro, pela apreciação crítica e exploratória que faz dos achados. O trabalho de coleta e análise dos dados, que durou vários meses, pretendeu ser mais do que um estudo bibliométrico e buscou qualificar um tema de grande relevância acadêmica e social. Como explicitado no método adotado, os artigos não figuram somente como números obtidos em leitura do tipo skimming ou categorizados aleatoriamente. A seleção do material seguiu critérios precisos e as categorias decorreram de atenta leitura dos textos selecionados, seguindo estágios bem definidos e encadeados de análise. O estudo evitou percursos já trilhados por muitos dos artigos avaliados, de resgate histórico, optando por uma análise mais concreta e reflexiva das experiências, para que o artigo pudesse efetivamente contribuir para o avanço da discussão das ações afirmativas na universidade.

Na próxima seção encontra-se o referencial teórico, em que contextualizamos ações afirmativas, partindo de eventos recentes e características históricas brasileiras, que explicam a reserva de vagas no ensino superior e que culminaram na aprovação da legislação atual. A terceira seção detalha o método utilizado no estudo e os diferentes estágios de seleção, avaliação e categorização do material utilizado. A análise dos resultados, quarta seção do artigo, é a mais robusta e está dividida em quantitativa e qualitativa, para melhor entendimento das particularidades do estudo. As conclusões sobre o estágio das produções na área, associadas a contribuições do presente estudo, são sintetizadas na última seção.

\section{As Ações Afirmativas}

A afirmação de direitos parte do reconhecimento de assimetrias sociais e do desequilíbrio em possibilidades de inclusão. As ações afirmativas originalmente se baseiam em críticas à ideia da igualdade de direitos, como meio de obtenção da igualdade social, acreditam, portanto, que os grupos ou pessoas socialmente desfavorecidos partem em desigualdade de possibilidades e têm menos chances de inclusão. As ações afirmativas raciais pretendem "restituir a igualdade de oportunidades (Ministerio do Trabalho e Emprego (2001, p. 10) entre os diferentes grupos raciais, promovendo um tratamento diferenciado e preferencial àqueles historicamente marginalizados" (Jaccoud \& Beghin, 2002, p. 46). O mesmo conceito pode ser aplicado a outros grupos em estado de vulnerabilidade econômica e social.

As ações afirmativas muitas vezes são percebidas pelo público em geral como tendo sido exclusivamente decididas por governos, reitorias, ou outras autoridades no exercício de seus 
cargos. A orientação de um governo, ou de uma gestão, favorece a celeridade de decisões ou da legislação, mas as ações afirmativas decorrem de anseios de origem popular. Além disso, não é somente a aprovação de uma lei ou a colocação em prática de uma decisão que impacta a sociedade mas, acima de tudo, as acomodações necessárias após a operacionalização da lei ou decisão. A alocação dos limitados recursos públicos é muito disputada e cria tensões e lutas por espaços entre diferentes grupos em uma dada realidade. Entender o processo de formulação e aprovação de políticas públicas é imprescindível para a abordagem do tema.

lizuka (2016), ao estudar a formulação de políticas públicas, desde quando a reivindicação passa a integrar a agenda formal de um governo ou autoridade, tenta reconstruir o percurso feito por temáticas oriundas de grupos minoritários até a esfera decisória. $O$ autor elegeu a reserva de cotas raciais nas universidades para compreender esse processo e os passos necessários para a efetivação das ações afirmativas. A formulação de políticas públicas, segundo essa reconstrução envolve desde a parte técnica, de coleta de indicadores e análise da conjuntura de determinada situação social, como por exemplo empregabilidade e anos de estudo, entre outros; até, e principalmente, aspectos políticos e concepções de sociedade, como caminhos de integração e inclusão racial, análise da presença de racismo e racismo institucional, papel social das universidades. O autor conclui que do ponto de vista técnico, a política de cotas raciais nas universidades apresentou falhas na coleta de dados relevantes e na legitimação de argumentos. O exemplo dado para embasar essas conclusões é de que, os mesmos dados sobre educação coletados podem favorecer ou não a implantação da política pública no ensino superior pois, mesmo que a presença de negros nas universidades seja pequena, pode-se contra-argumentar que seria necessária a ênfase na escola de base, como meio de garantir o acesso de futuras gerações. Por outro lado, do ponto de vista político, as políticas afirmativas na universidade favoreceram, entre outros, o debate sobre racismo no país. A crença na democracia racial brasileira teria sido redimensionada, uma vez que o tema da inclusão de negros na universidade passou a ser discutido e aplicado (lizuka, 2016).

A Lei 12.711/2012, chamada de lei de cotas nas universidades, colocou em discussão temas polêmicos e por tanto tempo relegados ao ostracismo na realidade brasileira. Não somente o racismo, como também a desigualdade social e de oportunidades entre estudantes provenientes de diferentes estratos sociais. Para os apoiadores, as mudanças no acesso ao ensino superior refletem em benefícios em outras esferas: desde direitos humanos, até razões mais práticas, de tipo econômico e de novas possibilidades de desenvolvimento social, sem falar, na superação e prevenção da pobreza e marginalização. Como colocado por Bezerra e Gurgel (2012), as políticas públicas que possam reparar, pelo menos em parte, as injustiças de acesso às oportunidades sociais seriam um imperativo ético. 
doi: http://doi.org/10.15359/ree.24-1.16

URL: http://www.una.ac.cr/educare

CORREO: educare@una.cr

\section{Método}

Após um breve e prévio contato das pesquisadoras com a temática das ações afirmativas percebeu-se uma miríade de publicações de momentos variados e com contextos históricos diferentes. Compreendeu-se, portanto, a necessidade de uma análise revisional ampla (quantitativa e qualitativa) sobre o tema e publicações para uma posterior pesquisa sobre as especificidades que se apresentavam. Uma revisão literária, seja ela crítica ou sistemática, requer o empreendimento de tempo, esforço e muita clareza de pesquisa, mas produz um panorama muito interessante sobre um tema. Para Zoltowski, Costa, Teixeira e Koller (2014) na área das ciências sociais e humanas não há uma tradição como há nas ciências biomédicas na produção de revisões sistemáticas. Contudo, ela é uma ferramenta que ajuda a organizar, analisar criticamente e sintetizar os resultados encontrados na literatura, resultando em um panorama do tema pesquisado (Zoltowski et al., 2014).

Para essa revisão bibliográfica crítica com rigor metodológico, agrupando elementos metodológicos de uma revisão sistemática ${ }^{4} \mathrm{com}$ aqueles de uma revisão crítica de literatura, foram consultadas as seguintes bases de dados eletrônicos: Scientific Eletronic Library (SciELO), Scientific Periodicals Electronic Library (SPELL) e base de dados da Associação Nacional de Pós-graduação e Pesquisa em Administração (ANPAD). As bases de dados foram escolhidas devido à gratuidade e à disponibilidade de acesso no ambiente universitário, assim como devido à presença de publicações nacionais e internacionais, conjugando temáticas interdisciplinares da Administração e Educação. A escolha pela base de dados ANPAD foi considerada pelas autoras uma vez que apresenta muitas vezes trabalhos ainda em desenvolvimento na academia, o que poderia permitir uma visão para que direção o tema viria a ser estudado no Brasil.

A pesquisa começou com o uso de palavras-chaves e suas combinações. As combinações foram predeterminadas de maneira que sempre houvesse um termo do tema central da pesquisa (ações afirmativas, affirmative actions, acción afirmativas, cota/quotas, cuotas, políticas raciais, racial politics/policies, políticas raciales, políticas sociais, social politics/ policies, políticas sociales, políticas de inclusão, inclusion policies/politics, políticas de inclusión) e um termo relativo a delimitação do contexto de pesquisa (ensino superior, post secondary education, educación superior, universidade, university, universidad). A associação palavra tema e palavra contexto das expressões citadas seguiu uma conformidade de idiomas, totalizando trinta e duas possibilidades de pesquisa em cada base, ou seja, 96 buscas nas três bases de dados. Cabe esclarecer que a pesquisa foi realizada em paralelo por duas diferentes pesquisadoras no mesmo período de tempo e utilizando o mesmo navegador para se evitar

${ }^{4}$ Utilizou-se a metodologia PRISMA.( Preferred Reporting Items for Systematic Reviews and Meta-Analyses, apresentada por Urrútia \& Bonfill (2010).

6 Daniela Basso-Poletto, Cora Efrom e Maria Beatriz-Rodrigues

Los artículos de la Revista Electrónica Educare del Centro de Investigación y Docencia en Educación de la Universidad Nacional, Costa Rica, se comparten bajo términos de la Licencia Creative Commons: Reconocimiento, № Comercial, Sin 0bra Derivada 3.0 Costa Rica. Las autorizaciones adicionales a las aquí delimitadas se pueden obtener en el correo: educare@una.cr 
qualquer desconformidade de resultados. Os termos foram pesquisados em português, inglês e espanhol. Optou-se pela utilização dos termos supracitados devido a inconformidade de achados prévios sobre o tema, dessa forma, o uso de expressões de amplo espectro de sentidos permitiria uma maior certeza da inclusão do que há sobre os temas para posterior exclusão, caso fugisse ao tema fim deste artigo. O período pré-determinado para a pesquisa foi de janeiro de 2007 até julho de 2017, tendo-se em vista o objetivo de discutir o estado do conhecimento e discussão sobre o tema.

Para a análise dos dados, materiais encontrados e a revisão, contou-se com a contribuição de três pesquisadoras para análise quantitativa, no qual a terceira pessoa ocupou a função de árbitro sobre as dúvidas e casos de discordância. $O$ árbitro foi escolhido considerando seu relevante conhecimento e qualificação para a pesquisa. O método de pesquisa foi determinado previamente ao seu início, para evitar possíveis vieses. As etapas da seleção de materiais encontram-se sumarizadas na Figura 1. A primeira etapa foi a coleta de todos os resultados para cada combinação de palavras nas três bases de maneira independente por cada pesquisadora, quando foram encontrados 1105 artigos. Posteriormente, o número total de registros foi sendo triado, conforme os critérios de exclusão objetivos previamente definidos em uma ordem fixa exposta a seguir: somente artigos, publicados de 2007 até 2017 (delimitação temporal da publicação) e idiomas (português, inglês e espanhol). A partir do resultado dessa seleção inicial, passou-se para a verificação e descarte dos materiais repetidos, o que demandou a adoção de três etapas $^{5}$. Na sequência, todos os títulos, os resumos e as palavras-chaves foram avaliados de forma independente pelos três pesquisadores para se decidir sobre a elegibilidade do artigo, quantificando e justificando a exclusão dos materiais desconsiderados, conforme a temática escolhida (associação com ações afirmativas e termos afins) e a delimitação do contexto (ensino superior/universidade). Foram considerados, ao final, para leitura integral e aprofundada, 119 artigos. A partir da leitura integral dos artigos por duas pesquisadoras para exame quantitativo e qualitativo se percebeu ainda a permanência de artigos repetidos com títulos diferentes (4 artigos optou-se pela permanecia naquele publicado em periódico ao invés de evento), indisponibilidade do texto integral ( 1 artigo) e artigos com tangenciamento no tema, mas sem enfoque com aprofundamento (19 artigos). Foram considerados, por fim, 96 para análise integral quantitativa e qualitativamente.

\footnotetext{
${ }^{5}$ Primeira: exclusão de duplicados dentro da mesma base de dados avaliando seus títulos (SciELO passou de 1038 para 231; SPELL passou de 53 para 19; ANPAD permaneceram em 14 artigos encontrados). Segunda etapa: exclusão materiais duplicados unindo-se todos os artigos triados nas três bases de dados, apreciando-se o título e subtítulo nos diferentes idiomas. Terceira etapa: triagem conforme o título, resumo e palavras-chaves. Os artigos que em seu título ou resumo não forneceram informações suficientes, com relação aos critérios de inclusão e exclusão foram todos selecionados para avaliação do texto integral, para que não se corresse o risco de perda de material para análise.
} 
doi: http://doi.org/10.15359/ree.24-1.16

URL: http://www.una.ac.cr/educare

CORREO: educare@una.cr

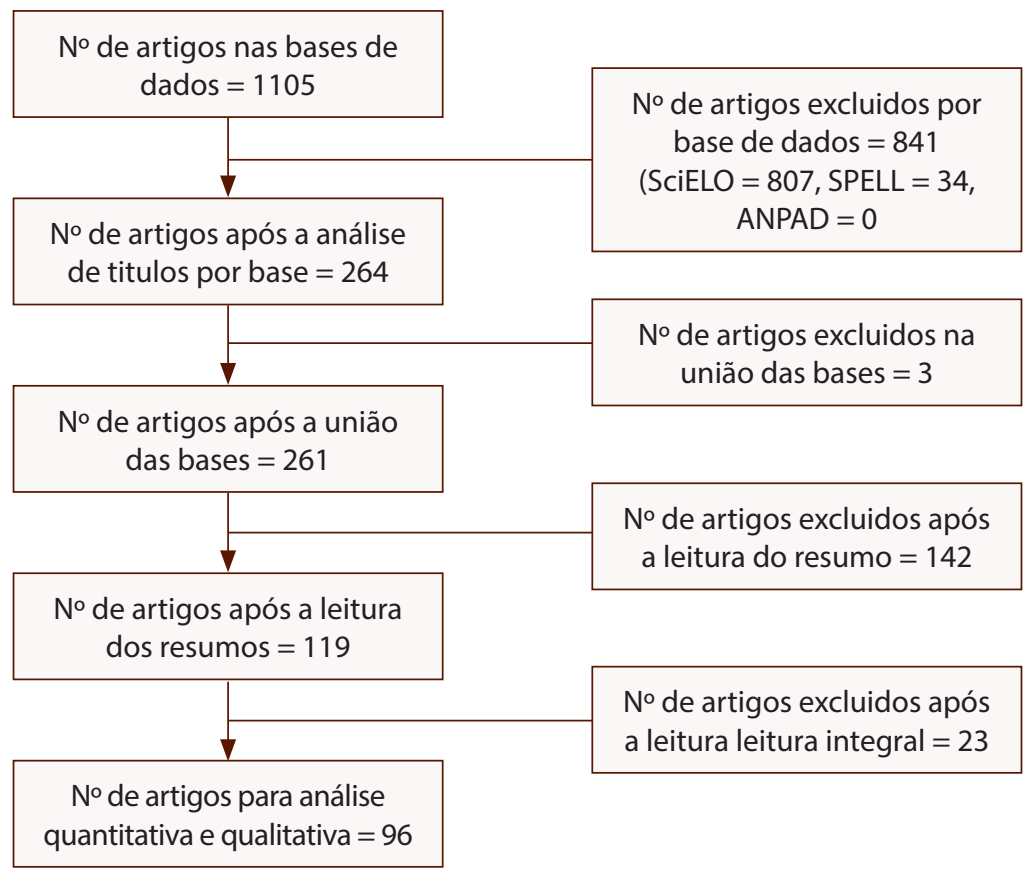

Figura 1: Fluxograma de seleção de materiais.

Nota: Elaborado pelas autoras.

Dentre as variáveis, apreciadas quantitativamente e pré-estabelecidas no início da pesquisa, estão aquelas analisadas por cálculo de frequência: autores, ano da publicação, periódico, nacionalidade dos autores, presença ou não de limitadores descritos pelos autores no artigo, apresentação do tipo de pesquisa escolhida para o artigo.

As variáveis analisadas qualitativamente foram categorizadas, após a leitura integral dos artigos, organizadas da seguinte forma: ações afirmativas no ensino superior em outros países; desempenho no acesso e na permanência entre alunos cotistas e/ou não-cotistas; estudos de caso em instituições de ensino superior específicas; momento histórico da publicação dos artigos; a questão da eficiência e eficácia das ações afirmativas para as instituições de ensino, para os indivíduos e para a sociedade. Para análise dos materiais selecionados e determinação das variáveis qualitativas, tendo em vista a heterogeneidade das metodologias e temáticas dos artigos, considerou-se o método de análise de conteúdo proposto por Bardin (2010), quando na exploração do material, para que as unidades de significado semelhantes fossem agrupadas, considerando recortes semânticos (temas) e linguísticos. Para isso, foram previamente concebidos que cada artigo estivesse em apenas um agrupamento por análise e que houvesse pertinência e objetividade da publicação com o objetivo da pesquisa. Ao final da análise dos artigos selecionados, foi feita uma síntese dos principais achados de acordo com cada variável. 
Ao longo de todo o trabalho houve o cuidado para seguir todos os preceitos éticos norteadores de uma pesquisa de revisão com constante verificação de dados, inclusão do artigo em caso de dúvida, autenticidade dos dados, devida referência aos materiais, clareza quanto a métodos e procedimentos. Conforme sua natureza crítica, esta revisão carrega consigo olhares e entendimentos dos seus pesquisadores, não necessariamente generalizáveis. Dessa forma, este estudo não traz consigo a passividade do pesquisador na mera agremiação e sintetização dos dados quantitativos, busca-se também explorar e refletir sobre as ações afirmativas/sistema de cotas ou outras denominações afins de forma a contribuir com o desenvolvimento nos campos das ciências exatas e sociais aplicadas. Os 96 artigos e suas referências encontram-se no Tabela 1.

Tabela 1: Referências dos 96 artigos finais que embasaram as análises quantitativas e qualitativas

1. Abitante (2017). O impacto da política pública de reserva de vagas sobre o desempenho acadêmico dos alunos em disciplina do curso de arquitetura e urbanismo da Universidade Federal do Rio Grande do Sul.

2. Albuquerque, \& Pedron (2015). Os Objetivos das Ações Afirmativas em uma IES Pública Brasileira: a Percepção da Comunidade Acadêmica.

3. Amaral, \& Baibich-Faria (2012). A presença dos estudantes indígenas nas universidades estaduais do Paraná: trajetórias e pertencimentos.

4. Andrade (2007). Effects of the brazilian university policy of targeting the poor.

5. Andrade (2010). Higher education: free tuition vs. quotas vs. targeted vouchers.

6. Aranha, Pena, \& Ribeiro (2012). Programas de inclusão na UFMG: o efeito do bônus e do Reuni nos quatro primeiros anos de vigência - um estudo sobre acesso e permanência.

7. Artes, \& Ricoldi (2015). Acesso de negros no ensino superior: o que mudou entre 2000 e 2010.

8. Baeta Neves (2014). Enseñanza superior em Brazil y las politicas de inclusión social.

9. Barreyro, \& Costa (2015). Las políticas de educación superior en Brasil en la primera década del siglo XXI: Algunas evidencias sobre impactos positivos en la equidad.

10. Barros, Melo, \& Lopes (2015). O Prouni e a Promoção do Empoderamento de Mulheres: Estudo com Egressas de uma Instituição de Ensino Superior Privada Mineira.

11. Batista (2015). Políticas públicas de ações afirmativas para a Educação Superior: o Conselho Universitário como arena de disputas.

12. Bayma (2012). Reflexões sobre a constitucionalidade das cotas raciais em Universidades Públicas no Brasil: referências internacionais e os desafios pós-julgamento das cotas.

13. Bevilaqua (2015). The institutional life of rules and regulations: ten years of affirmative action policies at the Federal University of Paraná, Brazil.

14. Bezerra, \& Gurgel (2012). A política pública de cotas em universidades, enquanto instrumento de inclusão social.

15. Bispo, \& dos Santos (2013). Uma análise do Programa Universidade para Todos e sua relação com a democratização do acesso ao Ensino Superior e a redução de desigualdades regionais.

16. Brandão, \& de Marins (2007). Cotas para negros no Ensino Superior e formas de classificação racial.

17. Camino, Tavares, Torres, Álvaro, \& Garrido (2014). Repertórios discursivos de estudantes universitários sobre cotas raciais nas universidades públicas brasileiras. 
doi: http://doi.org/10.15359/ree.24-1.16

URL: http://www.una.ac.cr/educare

CORREO: educare@una.cr

18. Campos, \& Feres (2014). Ação afirmativa, comunitarismo e multiculturalismo: relações necessárias ou contingentes?

19. Campos, Machado, Miranda, \& Costa (2017). Social quotas, affirmative actions, and dropout in the Business field: empirical analysis in a Brazilian federal university.

20. Casali, \& de Mattos (2015). Análise de estudos e pesquisas sobre o sentido social do programa Universidade para Todos (PROUNI).

21. Castro, Aranda, Castro, de Torres, Lizama, \& Williams (2014). Sistematización de la implementación del sistema de ingreso prioritario de equidad educativa (excupo de equidad) en la carrera de Psicología de la Universidad de Chile 2010-2012.

22. Cervi (2013). Ações afirmativas no vestibular da UFPR entre 2005 a 2012: de política afirmativa racial a política afirmativa de gênero.

23. Chávez Achong (2013). Universidad Nacional Agraria La Molina - Perú: inclusión social y discriminación social.

24. Chiroleu (2009). Políticas públicas de inclusión en la educación superior los casos de Argentina y Brasil.

25. Cicalò (2008). What Do We Know About Quotas? Data and Considerations About the Implementation of the Quota System in the State University of Rio de Janeiro (UERJ).

26. Cohen, Exner, \& Gandolfi (2016). Os Resultados da Implementação da Política de Cotas em um Campus Universitário Federal no Interior do Estado de Minas Gerais.

27. Colo (2013). Race and affirmative action: The implementation of quotas for "Black" students in a Brazilian University.

28. da Silva, Dias, \& da Silva (2014). Políticas Públicas de Ensino Superior: Fragilidades na Avaliação e Dificuldades para os Seus Beneficiários no Mercado de Trabalho.

29. Daflon, Feres, \& Campos (2013). Ações afirmativas raciais no ensino superior público brasileiro: um panorama analítico.

30. de Anhaia (2012). Políticas públicas e sociais para a equidade: um estudo sobre o programa universidade para todos.

31. de Jesus (2013). O desafio da convivência: assessoria de diversidade e apoio aos cotistas (2004-2008).

32. de Mello e Souza (2012). Desempenho dos candidatos no vestibular e o sistema de cotas na UERJ.

33. de Mendonça, Guerra, Mendonça, \& de Sousa Neto (2015). Políticas de Acesso à Educação Superior e Desempenho de Alunos Bolsistas: o Caso de uma Universidade Privada de Natal/RN.

34. de Oliveira, \& Molina (2012). A ampliação da base social da educação superior no contexto do Centro Universitário do Leste de Minas Gerais: o caso do ProUni.

35. de Souza, \& Teixeira Brandalise (2015). Democratização, justiça social e igualdade na avaliação de uma política afirmativa: com a palavra, os estudantes.

36. de Souza, \& Teixeira Brandalise (2016). Avaliação da política de cotas da UEPG: desvelando o direito à igualdade e à diferença.

37. do Amaral, \& de Oliveira (2011a). O Prouni e a conclusão do ensino superior: novas trajetórias pessoais e profissionais dos egressos.

38. do Amaral, \& de Oliveira (2011b). O ProUni e a conclusão do ensino superior: questões introdutórias sobre os egressos do programa na zona oeste do Rio de Janeiro.

39. dos Passos (2015). Relações raciais, cultura acadêmica e tensionamentos após ações afirmativas.

40. dos Santos, \& Scopinho (2016). Desigualdades Raciais, Mérito e Excelência Acadêmica: Representações Sociais em Disputa.

41. dos Santos, Cavalleiro, Barbosa, \& Ribeiro (2008). Ações afirmativas: polêmicas e possibilidades sobre igualdade racial e o papel do estado.

42. e Silva, \& da Silva (2012). Representações sociais de estudantes universitários sobre cotas na universidade.

43. Espinoza Díaz, \& González (2012). Políticas de educación superior en Chile desde la perspectiva de la equidad.

continúa

10

Daniela Basso-Poletto, Cora Efrom e Maria Beatriz-Rodrigues

Los artículos de la Revista Electrónica Educare del Centro de Investigación y Docencia en Educación de la Universidad Nacional, Costa Rica, se comparten bajo términos de la Licencia Creative Commons: Reconocimiento, № Comercial, Sin Obra Derivada 3.0 Costa Rica. Las autorizaciones adicionales a las aquí delimitadas se pueden obtener en el correo: educare@una.cr 
44. Felicetti, Cabrera, \& Costa-Morosini (2014). Aluno ProUni: impacto na instituçao de educação superior e na sociedade.

45. Felicetti, \& Costa-Morosini (2009). Equidade e iniquidade no ensino superior: uma reflexão.

46. Felicetti, \& Fossatti (2014). Alunos ProUni e não ProUni nos cursos de licenciatura: evasão em foco.

47. Feres, \& Daflon (2015). Ação afirmativa na Índia e no Brasil: um estudo sobre a retórica acadêmica.

48. Ferreiras, \& Mattos (2007). O afro-brasileiro e o debate sobre o sistema de cotas: um enfoque psicossocial.

49. Fontele, \& Crisóstomo (2016). PROUNI - pontos controversos sob a análise de alunos bolsistas.

50. Griner, Gomes, Sampaio, \& de Souza (2013). Políticas de cotas: desempenho acadêmico e determinantes de acesso à Universidade Federal do Rio Grande do Norte.

51. Griner, Sampaio, \& Sampaio (2015). A política afirmativa "Argumento de Inclusão" como forma de acesso à universidade pública: o caso da Universidade Federal do Rio Grande do Norte.

52. Guarnieri, \& Melo-Silva (2007). Ações afirmativas na educação superior: rumos da discussão nos últimos cinco anos.

53. Guarnieri, \& Melo-Silva (2010). Perspectivas de estudantes em situação de vestibular sobre as cotas universitárias.

54. Haas, \& Linhares (2012). Políticas públicas de ações afirmativas para ingresso na educação superior se justificam no Brasil?

55. Heringer, \& Honorato (2015). Elementos para uma análise dos estudantes cotistas e bolsistas no curso de pedagogia da UFRJ.

56. lizuka (2016). A Política de Cotas nas Universidades Brasileiras: Como ela Chegou à Agenda de Políticas Públicas?

57. Kern, \& Ziliotto (2011). Public university and social inclusion: the racial quotas for self-declared blacks in the federal university of Rio Grande do Sul.

58. Leite (2011). Política de cotas no Brasil: política social?

59. Lima, Neves, \& e Silva (2014). A implantação de cotas na universidade: paternalismo e ameaça à posição dos grupos dominantes.

60. Lloyd (2016). Una década de políticas de acción afirmativa en la educación superior brasileña: impactos, alcances y futuro.

61. Magnoni (2016). Lei de Cotas e a mídia brasileira: o que diria Lima Barreto?

62. Mata Carnevali (2008). India: Educación con reservas.

63. Matos, Pimenta, de Almeida, \& Oliveira (2012). O impacto do Programa de Inclusão Social da Universidade de São Paulo no acesso de estudantes de escola pública ao ensino superior público gratuito.

64. Mendes Junior (2014). Uma análise da progressão dos alunos cotistas sob a primeira ação afirmativa brasileira no ensino superior: o caso da Universidade do Estado do Rio de Janeiro.

65. Menin, Shimizu, da Silva, Cioldi, \& Buschini (2008). Representações de estudantes universitários sobre alunos cotistas: confronto de valores.

66. Mongim (2016). Itinerários de escolarização e mediações subjacentes: a experiência de discentes beneficiários do Prouni.

67. Moya (2011). Equidad en el acceso a la educación superior: los "cupos de equidad" en la Facultad de Ciencias Sociales de la Universidad de Chile.

68. Nery, \& Costa (2009a). Afetividade entre estudantes e sistema de cotas para negros.

69. Nery, \& Costa (2009b). Política afirmativa racial: polêmicas e processos de identidade do cotista universitário.

70. Neves, Faro, \& Schmitz (2016). As ações afirmativas na Universidade Federal de Sergipe e o reconhecimento social: a face oculta das avaliações.

71. Neves, \& Lima (2007). Percepções de justiça social e atitudes de estudantes pré-vestibulandos e universitários sobre as cotas para negros e pardos nas universidades públicas.

72. Nunes, \& Neira (2014). Processos de inclusão excludente presentes no ensino superior privado.

73. Osorio (2009). Classe, raça e acesso ao ensino superior no Brasil.

continúa 
doi: http://doi.org/10.15359/ree.24-1.16

URL: http://www.una.ac.cr/educare

CORREO: educare@una.cr

74. Paixão, Pereira, \& dos Santos (2015). Desempenho Acadêmico dos Alunos Declarados Cotistas e Não Cotistas do Curso de Bacharelado em Administração da Universidade Federal da Bahia.

75. Passos, \& Gomes (2014). A instituição da reserva de vagas na universidade pública brasileira: os meandros da formulação de uma política.

76. Paulo (2010). Preliminary studies on affirmative action in a Brazilian university.

77. Pedroza Flores, \& Villalobos Monroy (2009). Políticas compensatorias para la equidad de la educación superior en Argentina, Bolivia y Venezuela.

78. Peixoto, Ribeiro, Bastos, \& Ramalho (2016). Cotas e desempenho acadêmico na UFBA: um estudo a partir dos coeficientes de rendimento.

79. Picanço (2015). Juventude por cor e renda no acesso ao ensino superior: somando desvantagens, multiplicando desigualdades?

80. Piotto, \& Nogueira (2016). Incluindo quem? Um exame de indicadores socioeconômicos do Programa de Inclusão Social da USP.

81. Queiroz, Miranda, Tavares, \& de Freitas (2015). A lei de cotas na perspectiva do desempenho acadêmico na Universidade Federal de Uberlândia.

82. Ristoff (2014). O novo perfil do campus brasileiro: uma análise do perfil socioeconômico do estudante de graduação.

83. Rossetto, \& Gonçalves (2015). Equidade na Educação Superior no Brasil: Uma Análise Multinomial das Políticas Públicas de Acesso.

84. Santos (2012). Ações afirmativas no ensino superior: análise do perfil socioeconômico e da experiência universitária de bolsistas do ProUni na PUC-Rio.

85. Santos, de Souza, \& Sasaki (2013). O subproduto social advindo das cotas raciais na educação superior do Brasil.

86. Saraiva, \& Nunes (2011). A efetividade de programas sociais de acesso à educação superior: o caso do ProUni.

87. Serafim, \& Gomes (2015). Meritocracia e o Sistema de Cotas nas Universidades Brasileiras: um Estudo de Caso com Estudantes da Universidade Federal Rural do Semi-Árido (UFERSA).

88. Silva (2016). Ação Afirmativa para Ingresso de Negros no Ensino Superior: a Formação da Agenda Governamental segundo Atores-Chave.

89. Sito (2014). Disputas e diálogos em torno do conceito de "ações afirmativas" para o ensino superior no Brasil.

90. Souza, \& Menezes (2014). Programa Universidade para Todos (PROUNI): quem ganha o quê, como e quando?

91. Trevisol, \& Nierotka (2016). Os jovens das camadas populares na universidade pública: acesso e permanência.

92. Turgeon, Chaves, \& Wives (2014). Políticas de ação afirmativa e o experimento de listas: o caso das cotas raciais na universidade brasileira.

93. Velloso (2009). Cotistas e não-cotistas: rendimento de alunos da Universidade de Brasília.

94. Wainer \& Melguizo (2017). Políticas de inclusão no ensino superior: avaliação do desempenho dos alunos baseado no Enade de 2012 a 2014

95. Weller, \& Silveira (2008). Ações afirmativas no sistema educacional: trajetórias de jovens negras da universidade de Brasília.

96. Winther, \& Golgher (2010). Uma investigação sobre a aplicação de bônus adicional como política de ação afirmativa na Universidade Federal de Minas Gerais (UFMG).

Nota: Elaborado pelas autoras.

12

Daniela Basso-Poletto, Cora Efrom e Maria Beatriz-Rodrigues

Los artículos de la Revista Electrónica Educare del Centro de Investigación y Docencia en Educación de la Universidad Nacional, Costa Rica, se comparten bajo términos de la Licencia Creative Commons: Reconocimiento, № Comercial, Sin Obra Derivada 3.0 Costa Rica. Las autorizaciones adicionales a las aquí delimitadas se pueden obtener en el correo: educare@una.cr 


\section{Resultados}

\section{Análise quantitativa}

A análise quantitativa teve como finalidade traçar um panorama geral dos 96 artigos analisados em profundidade. Em relação a base pesquisada $82 \%$ deles são da base SciELO, 9\% da SPELL e 8\% da ANPAD. A grande disparidade deve-se ao fato de que a SciELO é uma grande base de dados que abrange periódicos de diferentes áreas de 14 países (www.scielo.org recuperado em julho de 2017), enquanto a base da SPELL abarca particularmente artigos científicos das áreas de Administração, Contabilidade e Turismo, publicadas a partir de 2008 (www.spell.org.br recuperado em julho de 2017) e a base da ANPAD engloba publicações dentro do campo das ciências administrativas, contábeis e afins apenas no Brasil (www.anpad.org.br recuperado em julho de 2017).

Sobre os autores dos artigos analisados, percebe-se que eles não se mantem produzindo ao longo do tempo, $90 \%$ deles publicaram apenas uma vez. Dos $10 \%$ dos autores que publicaram mais de uma vez, 6 deles tem 2 publicações sobre o tema e 2 tem 3 publicações. Isso nos leva a crer que o tema das ações afirmativas no ensino superior ainda não é um tema explorado e aprofundado de maneira contínua pelos pesquisadores. Esse dado é consubstanciado com o fato dos referenciais teóricos dos artigos analisados não disporem de uma base teórica sólida e comum. No que se refere ao ano de publicação dos artigos, $73 \%$ dos artigos analisados foram publicados entre 2012 e 2017 (Figura 2).

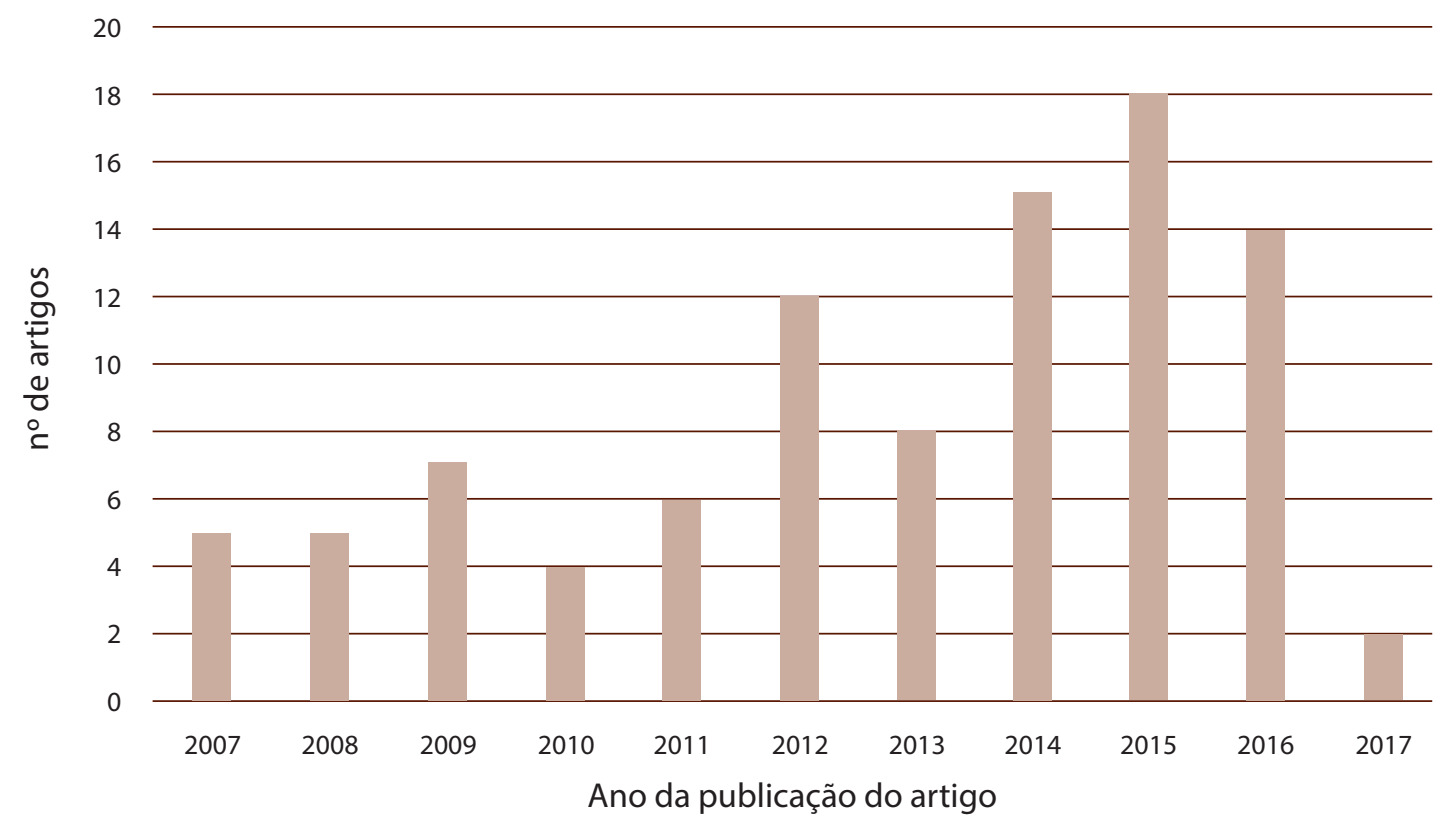

Figura 2: Número de artigos sobre ações afirmativas publicados por ano.

Nota: Elaborado pelas autoras. 
doi: http://doi.org/10.15359/ree.24-1.16

URL: http://www.una.ac.cr/educare

CORREO: educare@una.cr

Esse aumento de publicações ocorreu após a aprovação da Lei no 12.711 , de 29 de agosto de 2012. Mas antes da lei tornar obrigatória a reserva de vagas, muitas Instituições já estavam adotando a prática. Um levantamento feito pelo Laboratório de Políticas Públicas da UERJ, publicado em janeiro de 2009, demonstra que 51 instituições adotavam ações afirmativas no Brasil, entre universidades estaduais e federais, faculdades, centros universitários e Cefets (e Silva \& da Silva, 2012). Esses dados expõem a existência de um campo para pesquisa sobre o tema, porém se percebe que o interesse dos pesquisadores aumentou após a publicação da lei.

No que se diz respeito às publicações, os 96 artigos estão publicados em 51 periódicos/anais de eventos diferentes. Há um grande espalhamento em periódicos, contudo, percebendo-se que há uma grande concentração de publicações na área da educação. Dos resultados encontrados, 14\% dos artigos estavam no periódico Ensaio: Avaliação e Políticas Públicas em Educação, que contém a maior concentração de publicações. Não foi possível um detalhamento maior sobre as áreas temáticas em que os artigos foram publicados e, portanto, a que classificação Qualis Capes ${ }^{6}$ o periódico teria naquela área, uma vez que a grande maioria dos periódicos não dispõe claramente a que área um artigo se inseria (educação, administração, interdisciplinaridade, etc). Tal fato fez com que as pesquisadoras optassem por não classificá-los dessa maneira. Outro ponto a observar foi a existência de 10 artigos que foram apresentados em eventos da ANPAD e não foram publicados em outros meios. É possível se presumir, então, que pesquisas sobre o tema estão sendo realizadas, sem necessariamente estarem sendo publicadas em meios impressos ou digitais de periódicos, que disseminam a informação de maneira mais perdurável e com possibilidade de acesso que extravase aos sujeitos presentes em eventos.

Quanto à nacionalidade, $85 \%$ dos autores são de nacionalidade brasileira. Isso pode ser resultado da escolha das bases, visto que duas delas eram nacionais e na terceira o Brasil é o maior contribuidor de artigos. Outro ponto a se refletir nesse aspecto é o período escolhido para análise, já que o assunto estava em veemente discussão no Brasil no período pesquisado.

No que concerne as limitações dos estudos pesquisados, 78\% deles não apresentam limitações em relação as suas pesquisas. O não reconhecimento das limitações pela grande maioria dos autores pode encobrir as fragilidades dos estudos. Ao contrário do que muitos pensam, admitir as vulnerabilidades da sua pesquisa agrega mais credibilidade, mostrando que o estudo não é só de caráter opinativo, enviesado e que dados não foram convenientemente selecionados, mas permite dar um caráter mais científico e também permite que futuros pesquisadores evoluam nos seus estudos já considerando dificuldades ou fragilidades por vezes impensadas a priori.

\footnotetext{
${ }^{6}$ Qualis Capes é o sistema de classificação de periódicos quanto a qualidade dos conteúdos publicados.
} 
Em relação ao tipo de pesquisa, 43\% dos estudos são qualitativos, 35\% quantitativos e $22 \%$ são quantitativos-qualitativos. As autoras observaram também um grande número de estudos sobre desempenho entre cotistas e não-cotistas, seja sob um olhar quali, quanti como quantiquali. O enfoque nos estudos comparativos de cotistas e não-cotistas gerou muitas reflexões por parte das pesquisadoras. O que se percebeu é que, por vezes, o estudo é feito no mesmo local em que o pesquisador/autor estuda/trabalha. Será que tantos estudos comparativos se justificam pela facilidade de acesso a dados sem se precisar ir a outros campos? Dos 96 artigos analisados, 57 deles, mais da metade, utilizaram apenas dados de uma Instituição de Ensino Superior (IES) para seu estudo. Dessas Universidades estudadas, sua distribuição regional demonstra que os estudos se concentraram em IES das regiões Sudeste (20), Sul (12), Nordeste (12), Distrito Federal (7) e Norte (1). Esses dados mostram não só o enfoque na prática de ações afirmativas em uma única instituição por pesquisa, mas também leva a questionamentos sobre o acompanhamento científico dessas práticas nas regiões do país. Pode-se considerar, portanto, que diversas IES não tiveram suas práticas de inserção e permanência das ações afirmativas investigadas e que os estudos não permitem generalizações factíveis de suas práticas como realidade nacional ou regional. Ou seja, o processo indutivo utilizado por muitos desses estudos de caso de uma IES não deixa claro regras utilizadas. As pesquisadoras deste artigo entendem a necessidade de esclarecer que nos estudos qualitativos não há simplesmente um enfoque diverso do quantitativo, numérico, mas maior abertura para que se possa compreender as ações afirmativas de maneira mais complexa e multivariada, não tendo por obrigação a necessidade de generalização, mas a possibilidade de se observar aspectos peculiares e pertinentes às ações afirmativas. Infelizmente, o que se percebeu em alguns artigos, contudo, foi o uso de pesquisas qualitativas como permissíveis aos autores dos artigos para exercerem um posicionamento crítico e opinativo, com sujeitos de pesquisa elegidos, sem necessariamente apresentarem fundamentação teórica dos seus achados, fragilizando assim as informações apresentadas.

\section{Análise qualitativa}

\section{As ações afirmativas no ensino superior em outros países}

Na Tabela 2 estão descritas algumas ações afirmativas praticadas no ensino superior em diversos países, inclusive no Brasil. A análise deste quadro é importante para verificar a eficiência das políticas em outros países que as adotaram há mais tempo. O que cabe esclarecer, é que cada ação foi pensada dentro de um contexto político, econômico e social, não sendo possível, simplesmente, reproduzir a política que teve sucesso em um país e aplica-la ao Brasil. É importante explicitar que as ações expostas não são as únicas nestes países, mas aquelas citadas nos artigos pesquisados. 


\section{doi: http://doi.org/10.15359/ree.24-1.16}

URL: http://www.una.ac.cr/educare

CORREO: educare@una.cr

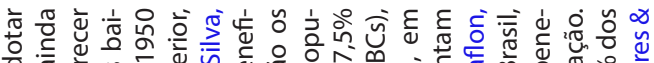

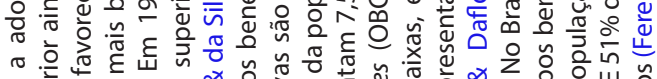

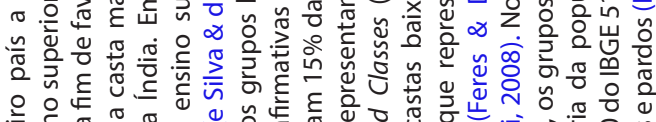

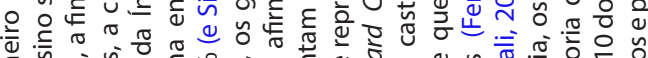

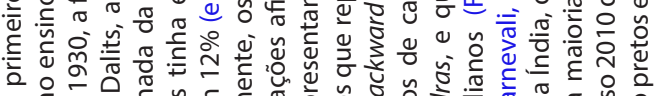

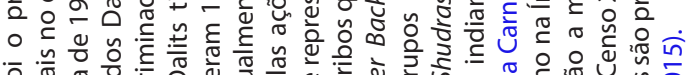

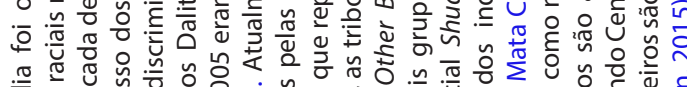

范

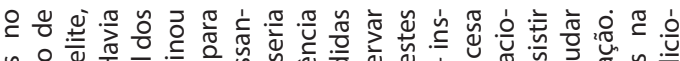

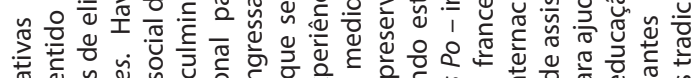

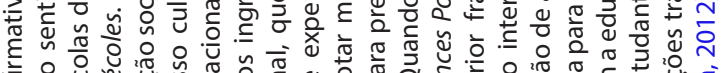

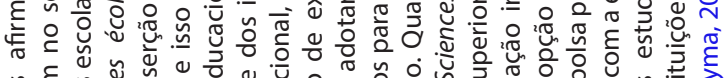

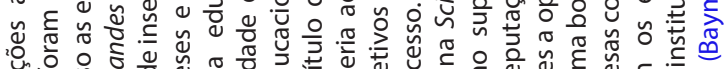

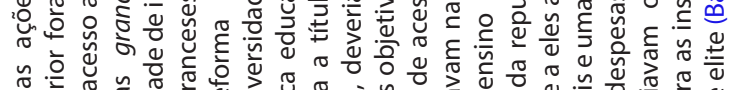

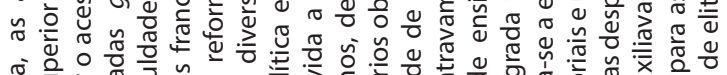

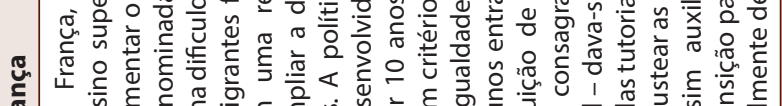

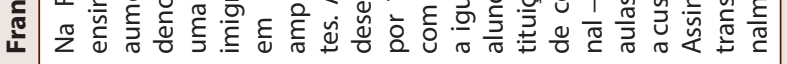

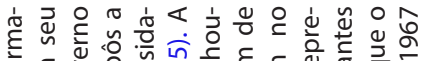

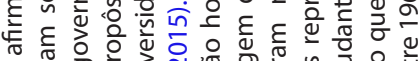

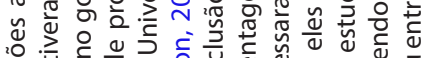

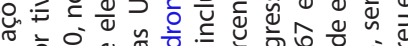

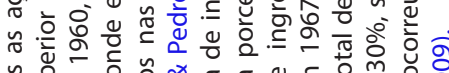

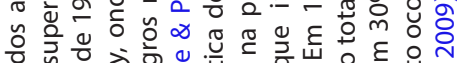

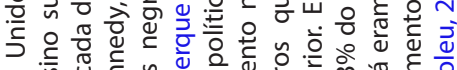

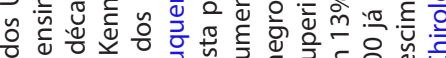

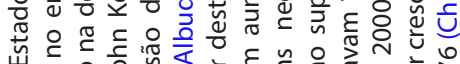

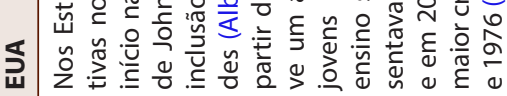

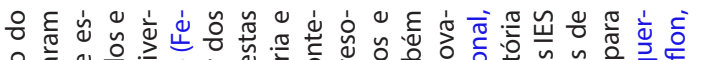

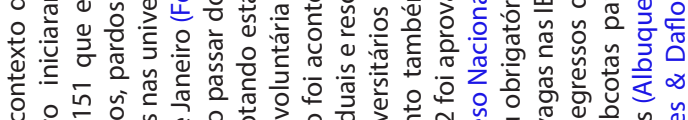

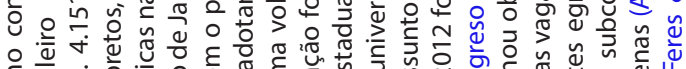

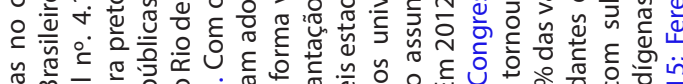

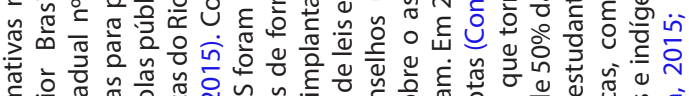

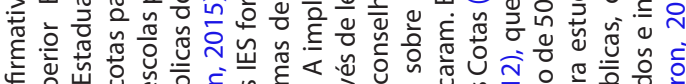

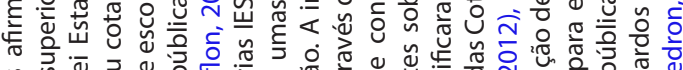

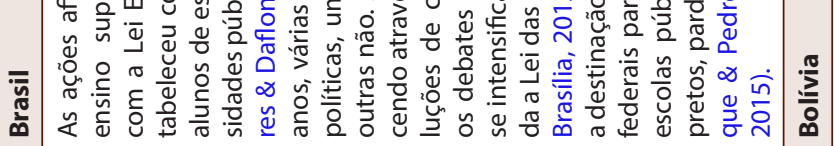

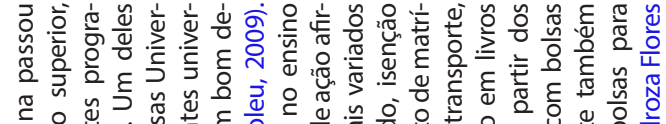

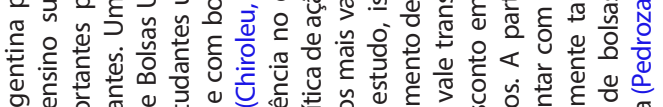

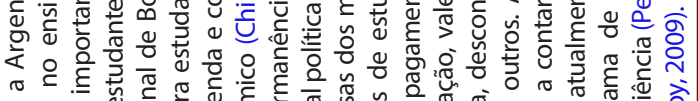

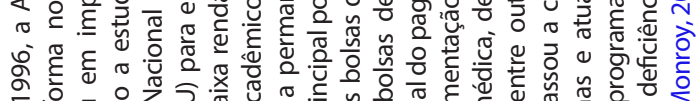

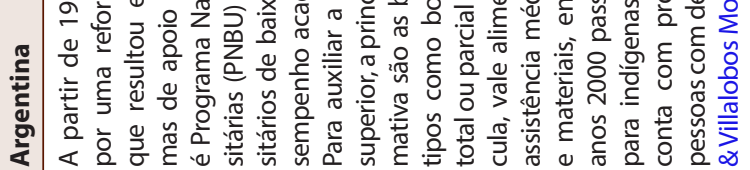

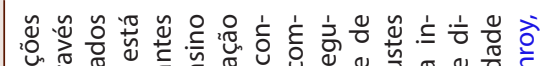

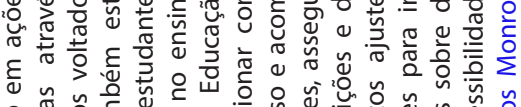

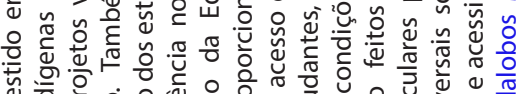

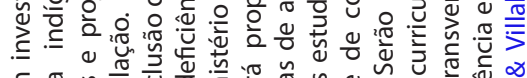

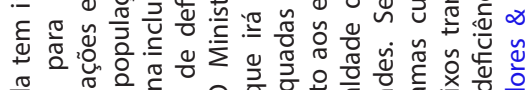

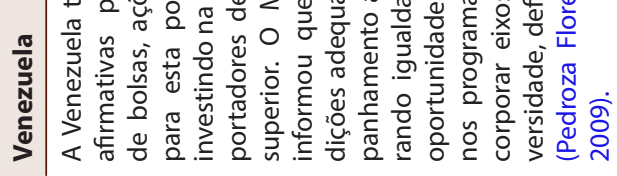

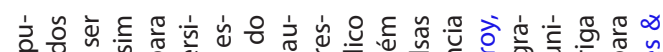

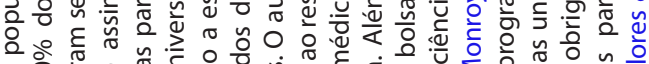

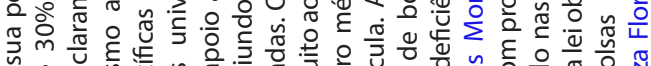

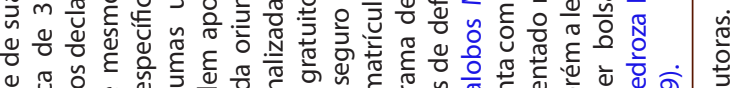

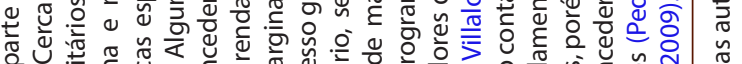

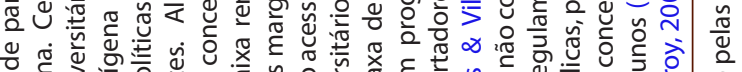

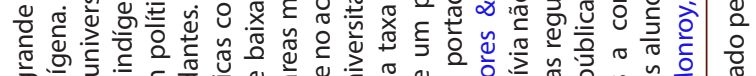

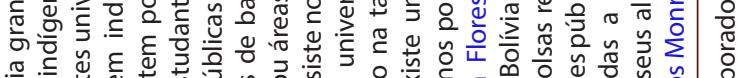

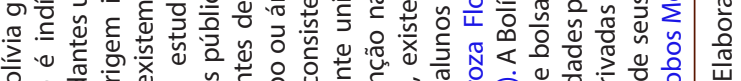

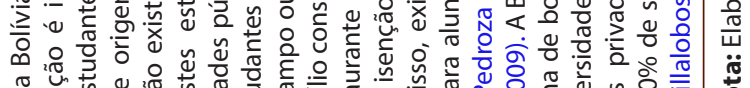

16

Daniela Basso-Poletto, Cora Efrom e Maria Beatriz-Rodrigues

Los artículos de la Revista Electrónica Educare del Centro de Investigación y Docencia en Educación de la Universidad Nacional, Costa Rica, se comparten bajo términos de la Licencia Creative Commons: Reconocimiento, № Comercial, Sin Obra Derivada 3.0 Costa Rica. Las autorizaciones adicionales a las aquí delimitadas se pueden obtener en el correo: educare@una.cr 


\section{Acesso e Desempenho de cotistas e não cotistas}

Entre os 96 artigos analisados em profundidade, há um grande número de estudos comparativos entre cotistas e não cotistas. Os dados utilizados para análise são geralmente dados censitários, dados do Exame Nacional de Desempenho de Estudantes (ENADE), índice de rendimento no vestibular, dados do perfil socioeconômico dos ingressantes. Algumas análises são mais específicas - comparando alunos de um mesmo curso (cotistas e não-cotistas) - e outras mais genéricas - comparando vários vestibulares e/ou vários cursos em uma mesma instituição-.

No que se refere ao acesso, Mendes Junior (2014) destaca que o desempenho dos não cotistas em termos de coeficiente de rendimento médio no processo seletivo é superior, enquanto Queiroz et al. (2015) diz que não existe diferença significativa de desempenho entre cotistas e não cotistas. Griner et al. (2013) observam que não existe diferença significativa de desempenho entre estudantes cotistas étnicos e os demais e ressalta que a renda familiar e a escola de origem afetam o desempenho dos candidatos. Segundo ele, os melhores resultados no vestibular ainda são dos alunos oriundos da escola privada.

Souza (2012) também concorda com a importância do ambiente familiar no desempenho dos candidatos, tanto diretamente, atuando através da renda familiar, da escolaridade dos pais, escola de origem, como indiretamente, através das carreiras selecionadas pelos candidatos. O autor também percebe que o desempenho entre os alunos subiu com o aumento da dificuldade relativa do curso, porque uma carreira de maior prestígio requer um conhecimento acumulado para garantir a aprovação. Souza (2012) enfatiza que mesmo os cotistas tendo as vagas restritas a eles, desde que satisfeita a classificação, muitos desistem de disputar uma vaga em carreira de prestígio devido às suas exigências após a aprovação.

Segundo Bezerra e Gurgel (2012) e Griner et al. (2013) para que o acesso possa acontecer de forma meritocrática sem as cotas é preciso que haja investimento na educação de base, de modo a permitir uma paridade entre os estudantes independente de sua origem. Para Bezerra e Gurgel (2012) os números no vestibular, são sem dúvida, a prova da desigualdade em relação a educação de base que tiveram acesso os estudantes cotistas. Espinoza Díaz e González (2012) apontam que assim como no Brasil, também em outros países da América Latina, a reserva de vagas não resolve o problema da inclusão de grupos minoritários, muitos estudantes nem alcançam este nível de educação formal.

Em relação à permanência, uma vez admitidos na Universidade, o aproveitamento dos cotistas ao longo do tempo vai invertendo os números negativos e os assemelhando aos resultados dos não-cotistas (Bezerra \& Gurgel, 2012; Griner et al., 2013; Velloso, 2009). Mendes Junior (2014, p. 52) afirma "que a persistência dos cotistas é maior e isto se traduz em maiores taxas de graduação." Porém, "não são fáceis as condições de permanência do cotista na Universidade brasileira”, destacam Bezerra e Gurgel (2012, p. 112).“De um lado, estas instituições 
doi: http://doi.org/10.15359/ree.24-1.16

URL: http://www.una.ac.cr/educare

CORREO: educare@una.cr

não oferecem [muitas] formas ... de acolhimento aos estudantes; do outro, [grande parte destes] alunos não possui condições de sobreviver a um curso acadêmico, ... [seja pelo] alto custo, ... transporte, ... aquisição de material didático" (Bezerra e Gurgel, 2012, p. 112), o curso ser diurno e não ser possível conciliar com o trabalho. Segundo esses autores, esses são alguns motivos que justificam as chances de uma evasão.

Para Bezerra e Gurgel (2012, p.112)

há ainda o fato de que a maioria dos alunos cotistas chega com grande deficiência de conteúdo, como provam os resultados por eles obtidos no exame vestibular. Essa deficiência, que os faz vivenciar a diferença em relação aos seus colegas ... é [também um] desestímulo a continuar.

Bezerra e Gurgel (2012, p. 112) frisam que, apesar "da evidente determinação do estudante cotista, a política de cotas necessita de algo mais do que simplesmente a reserva de vagas" para sua finalidade ser atendida.

Ao se analisar após a conclusão do curso, alguns autores como Wainer e Melguizo (2017, p. 12) destacam que "os alunos que se beneficiaram de uma política de [cotas] não terminam do ensino superior como profissionais de menor qualidade" e isso lhes permitiria melhor colocação no mercado de trabalho. Os retornos e benefícios dessas ações não se traduzem em ganhos somente em âmbito pessoal, mas para toda a sociedade.

Fica claro e as pesquisadoras deste artigo pactuam com os autores como Felicetti e Costa Morosini (2009) que as ações afirmativas no ensino superior precisam ser pensadas e termos de acesso, oportunidades, acompanhamentos e resultados.

\section{Momento histórico da publicação dos artigos e legislação}

Na análise realizada no tocante ao momento da publicação, percebeu-se uma concentração maior de artigos publicados no ano de 2014(14), 2015(17) e 2016(14), totalizando quase a metade dos artigos triados nos 10 anos considerados para essa pesquisa. Essa concentração de artigos deve-se principalmente ao momento histórico das ações afirmativas no Brasil, uma vez que a Lei Federal $n^{\circ} .12 .711$ de 2012 exigia que:

Art. $8^{\circ}$ As instituições de que trata o art. $1^{\circ}$ desta Lei deverão implementar, no mínimo, $25 \%$ (vinte e cinco por cento) da reserva de vagas prevista nesta Lei, a cada ano, e terão o prazo máximo de 4 (quatro) anos, a partir da data de sua publicação, para o cumprimento integral do disposto nesta Lei. (Congreso Nacional, Brasília, 2012) 
Dessa forma, a lei determina o aumento gradual do percentil de cotas, atingindo pelo menos " $50 \%$ (cinquenta por cento) de suas vagas para estudantes que tenham cursado integralmente o ensino médio em escolas públicas" (Congreso Nacional, Brasília, 2012, párr. 2) ao final dos 4 anos, o que seria em 2016. Cabe destacar ainda que esse percentil de vagas deve ocorrer em cada curso da instituição e que a metade das vagas reservadas deverão ser preenchidas por "estudantes oriundos de famílias com renda igual ou inferior a 1,5 saláriomínimo (um salário-mínimo e meio) per capita", Lei 12.711, 2012, artigo 1, §único, (Congreso Nacional, Brasília, 2012, párr. 2).

Outra observação pertinente se refere a alteração da mesma lei de 2012, quando através da lei no 13.409, de dezembro de 2016 (Congreso Nacional, Brasília, 2016). Essa última alterou a redação da lei 12.711 de 2012 em 3 artigos, determinando:

Art. $3^{\circ} \mathrm{Em}$ cada instituição federal de ensino superior, as vagas de que trata o art. $1^{\circ}$ desta Lei serão preenchidas, por curso e turno, por autodeclarados pretos, pardos e indígenas e por pessoas com deficiência, nos termos da legislação, em proporção ao total de vagas no mínimo igual à proporção respectiva de pretos, pardos, indígenas e pessoas com deficiência na população da unidade da Federação onde está instalada a instituição, segundo o último censo da Fundação Instituto Brasileiro de Geografia e Estatística - IBGE.

Art. $5^{\circ} \mathrm{Em}$ cada instituição federal de ensino técnico de nível médio as vagas de que trata o art. $4^{\circ}$ desta Lei serão preenchidas, por curso e turno, por autodeclarados pretos, pardos e indígenas e por pessoas com deficiência, nos termos da legislação, em proporção ao total de vagas no mínimo igual à proporção respectiva de pretos, pardos, indígenas e pessoas com deficiência na população da unidade da Federação onde está instalada a instituição, segundo o último censo do IBGE.

Art. $7^{\circ}$ No prazo de dez anos a contar da data de publicação desta Lei, será promovida a revisão do programa especial para o acesso às instituições de educação superior de estudantes pretos, pardos e indígenas e de pessoas com deficiência, bem como daqueles que tenham cursado integralmente o ensino médio em escolas públicas. (Redação dada pela Lei no 13.409, de 2016, grifo nosso). (Congreso Nacional, Brasília, 2012, párr. 6, 11, 15)

A alteração da legislação em 2016 insere as pessoas com deficiência na reserva de vagas, considera também as diferenças estaduais na distribuição de determinadas populações, utilizando-se o censo do IBGE, inclui o acesso a instituições de ensino médio técnico e, por fim, demanda a revisão desse programa de acesso às vagas no prazo de 10 anos. 
doi: http://doi.org/10.15359/ree.24-1.16

URL: http://www.una.ac.cr/educare

CORREO: educare@una.cr

Não podemos esquecer que a política de inclusão, exigida pela lei de 2012 e editada em 2016, vem em consonância e em conjunto com outras políticas públicas em execução no país. Como por exemplo, a expansão das IES (através da Reestruturação e Expansão das Universidades Federais [REUNI]) e as bolsas de estudo em universidades particulares para estudantes de baixa renda (através do Programa Universidade para Todos [PROUNI], desde 2004). Os artigos que costumam analisar posturas pró ou contra das ações afirmativas ou do acesso de determinados grupos populacionais, parecem se concentrar nos primeiros anos analisados por esta pesquisa revisional (exemplos: dos Santos et al., 2008; Guarnieri \& Melo-Silva, 2007; Menin, et al., 2008). Ou seja, havia e ainda há um momento histórico propício e necessário para a produção de estudos na academia sobre sua criação, continuidade e melhoria das ações afirmativas, mas como a sociedade do seu tempo e a exigência legal dessas ações, os enfoques abordados parecem não mais binários (pró ou contra).

Assim, a maior concentração de publicações se deveu a efervescência do tema no período. O amadurecimento das discussões (especialmente após a implantação da reserva de vagas nas instituições estaduais e federais) e a necessária proeminência da colocação em prática pelas Instituições de Ensino Superior de até 50\% de suas vagas reservadas em 2016 mostra-se diretamente relacionada ao aumento de publicações nesse período (2014-2016). A mudança da legislação em 2016 vem a acompanhar as complexidades percebidas nos anos anteriores (também presente nos artigos considerados nesta revisão) para se sanar as prováveis desigualdades criadas pela lei anterior (2012) que não se atinha às diferenças regionais (citado, por exemplo, por Bispo \& dos Santos, 2013; Serafim \& Gomes, 2015) e instaura a imprescindível revisão do programa. Da Silva et al. (2014) mencionam, por exemplo, a necessidade de avaliação das políticas públicas nas IES.

\section{Eficiência e eficácia das ações afirmativas nas IES?}

A presente análise revisional permitiu observar o grande enfoque dado para o estudo e se as ações afirmativas no ensino superior fazem aquilo que tem de ser feito como objetivo último: reduzir as desigualdades no acesso às IES. Outro enfoque dado é se os meios adotados são os melhores para se atingir os objetivos de reparação histórica e de busca por uma sociedade mais igualitária. Dessa forma, as abordagens e elementos que antecedem ou que sobrevêm a implantação das ações afirmativas, optados pelos diferentes autores nas suas publicações, acabam sempre por recair sobre esses objetivos direta ou indiretamente. Primeiramente, fica claro que a complexidade dessas análises sobre ações afirmativas nos artigos e a miríade de elementos que fazem sua interface não se exaurem na produção de um artigo ou estudo publicado, mas apenas pincela aspectos pontuais, o que, de certa forma, explica a presença da grande quantidade de estudos de caso nesta revisão (57 estudos). Sofre-se, portanto, com a escassez de análises mais amplas e regionalizadas, integrando-se diferentes IES. Além disso, percebem-se que há particularidades e há escolhas por diferentes abordagens nos artigos

20 Daniela Basso-Poletto, Cora Efrom e Maria Beatriz-Rodrigues

Los artículos de la Revista Electrónica Educare del Centro de Investigación y Docencia en Educcción de la Universidad Nacional, Costa Rica, se comparten bajo términos de la Licencia Creative Commons: Reconocimiento, № Comercial, Sin Obra Derivada 3.0 Costa Rica. Las autorizaciones adicionales a las aquí delimitadas se pueden obtener en el correo: educare@una.cr 
revisados, dificultando suas aproximações. Sabendo-se disso, optou-se pela apresentação deste subtema (eficácia e efetividade das ações afirmativas) sob o ponto de vista dos atores envolvidos?: dos indivíduos, das instituições de ensino superior e da sociedade.

Ao se observar a eficiência e eficácia das ações afirmativas no que concerne ao indivíduo, é possível identificar meios de análise diversos, sendo os estudos mais frequentes aqueles de caráter comparativos entre aqueles que são ou não cotistas/bonistas. Essas contraposições miram principalmente no desempenho no processo de acesso a IES (dos Santos \& Scopinho, 2016; Trevisol \& Nierotka, 2016; Velloso, 2009), no desempenho ao longo do curso (Abitante, 2017; Bezerra \& Gurgel, 2012; Cohen et al., 2016; Griner, et al., 2013; Mendes Junior, 2014; Paixão et al., 2015; Queiroz et al., 2015; Wainer \& Melguizo, 2017), na evasão (Bezerra \& Gurgel, 2012; Campos, et al., 2017; do Amaral \& Oliveira, 2011a; Trevisol \& Nierotka, 2016), na inserção no mercado de trabalho (da Silva et al., 2014; do Amaral \& Oliveira, 2011a). Tais estudos optam por agrupar situações individuais para sua análise como forma de investigação das práticas de inclusão. Constatou-se que a fragilidade dessas análises individuais está na dificuldade de generalização, sob um ponto de vista estatístico populacional, servindo como caráter exemplificativo de situações locais. Contudo, tais dados permitem a elucidação das percepções dos alunos e a exposição de situações e fatos que requerem reflexão, por exemplo, autopercepção dos alunos (Cohen et al., 2016; dos Santos \& Scopinho, 2016; Felicetti et al., 2014; Nery \& Costa, 2009b; Neves et al., 2016; Paulo, 2010); discriminação na IES (Kern \& Ziliotto, 2011; Paulo, 2010) num âmbito subjetivo e não simplesmente quantificável. Busca-se a partir do estudo de alunos justificar a existência ou não de políticas de inclusão, apoiando-se através dos estudos comparativos se estão ou não cumprindo da melhor forma possível com seu propósito último, deixando que o indivíduo tenha acesso a educação superior.

Do ponto de vista da IES como ator na análise das publicações sobre ações afirmativas, percebemos a priori duas grandes diferenças: a produção de estudos com enfoque nas instituições públicas (federais e estaduais) e nas instituições privadas. Ambas afetadas por políticas governamentais de inclusão de maneiras diferentes, uma vez que as IES privadas tem maior liberdade de adesão a esses programas sociais estatais. Sob esse olhar, os estudos apresentam a análise do PROUNI para IES privadas (Barros et al., 2015; Bispo \& dos Santos, 2013; de Anhaia, 2012; de Mendonça et al., 2015; de Oliveira \& Molina, 2012; do Amaral \& Oliveira, 2011a; Felicetti et al., 2014; Fontele \& Crisóstomo, 2016; Wainer \& Melguizo, 2017), política de quotas para IES públicas (Albuquerque \& Pedron, 2015; Kern \& Zilotto, 2011; Silva, 2016). Constatamos também a grande preocupação das IES com a perda ou ganho de qualidade após a implantação de políticas de inclusão (da Silva et al., 2014; dos Passos, 2015), uma vez que as IES públicas e privadas são ranqueadas nacional e internacionalmente e a alocação de recursos e pesquisas, especialmente no caso das instituições públicas, advém da sua posição.

\footnotetext{
${ }^{7}$ Considerando a análise de conteúdo, os atores envolvidos foi a categoria de agregação dos artigos analisados tendo em vista seus mais variados objetivos, bases teóricas e conteúdo opinativo.
} 
doi: http://doi.org/10.15359/ree.24-1.16

URL: http://www.una.ac.cr/educare

CORREO: educare@una.cr

Por fim, a sociedade é vista também como ator diretamente envolvido quando se fala em ações afirmativas, notadamente devido as suas consequências, conforme os estudos selecionados. O objetivo maior, reparação histórica e social, assim como a maior igualdade de acesso à educação superior repercutem não só nos indivíduos e instituições, mas refletem e dinamizam a sociedade. De forma geral os artigos citam os reflexos coletivos dessas ações numa predição de melhoria social com menores desigualdades (Barros et al., 2015; Bezerra \& Gurgel, 2012; da Silva et al., 2014; dos Passos, 2015; dos Santos et al., 2008; Felicetti et al., 2014; Kern \& Zilotto, 2011; Rossetto \& Gonçalves, 2015; Silva, 2016; Trevisol \& Nierotka, 2016, etc.). Alguns artigos questionam a efetividade das políticas afirmativas, pois teriam caráter focal e sintomático (Neves \& Lima, 2007) sem a necessária reformulação da base educacional que traria ao último grau da educação déficits e dificuldades que os precedem, não abrindo o real acesso a educação superior a todos (Amaral \& Baibich-Faria, 2012; Cohen et al., 2016; Paixão et al., 2015). Fica claro para as autoras que é imprescindível que novos estudos de caráter mais holístico dos atores envolvidos no processo de continuidade das ações afirmativas precisam ser realizados.

\section{Considerações Finais}

Esta pesquisa revisional propõe um resgate das publicações sobre ações afirmativas, sem limitar-se em sintetizar os resultados encontrados nos últimos dez anos. As pesquisadoras também exploraram e refletiram sobre os temas que mais apareceram na pesquisa com a finalidade de contribuir para o debate teórico sobre o tema. O trabalho de coleta e análise dos dados se distingue na qualificação de um tema de grande relevância acadêmica e social, no Brasil e no mundo, assim como, e em decorrência, na análise qualitativa e quantitativa de artigos sobre o tema. Mesmo considerando que o foco da pesquisa tenha sido nas experiências concretas, mais do que no resgate histórico de diferentes países.

Como mencionado, o método adotado seguiu uma criteriosa seleção e leitura dos textos em evidência, com estágios de tratamento dos resultados bem definidos e encadeados, guiados por relevantes categorias de análise. A reflexão resultante desse processo pretendeu entender e contribuir efetivamente para o avanço da discussão das ações afirmativas nas universidades.

É necessário destacar que o objetivo deste artigo é uma análise revisional do tema no contexto estabelecido para esta pesquisa, apesar do cauteloso rigor metodológico na seleção e inclusão dos materiais, buscou-se também uma apreciação crítica e exploratória dos achados, contendo, portanto, limitações quanto aos idiomas pesquisados, inclusão de outras bases de dados, limitações das combinações de busca. Ao contrário da expectativa das autoras, a base de dados ANPAD, escolhida a priori para esta pesquisa, não trouxe uma contribuição significativa. As publicações nessa base de dados tende a apresentar ensaios ou pesquisas em andamento no cenário acadêmico brasileiro, o que poderia ter permitido um olhar sobre o desenvolvimento da reflexão sobre o tema das ações afirmativas no Brasil. Contudo, essa expectativa não se

Daniela Basso-Poletto, Cora Efrom e Maria Beatriz-Rodrigues

Los artículos de la Revista Electrónica Educare del Centro de Investigación y Docencia en Educcción de la Universidad Nacional, Costa Rica, se comparten bajo términos de la Licencia Creative Commons: Reconocimiento, № Comercial, Sin Obra Derivada 3.0 Costa Rica. Las autorizaciones adicionales a las aquí delimitadas se pueden obtener en el correo: educare@una.cr 
concretizou pois todas as publicações triadas na ANPAD estiveram repetidas em alguma das outras bases (Scielo e SPELL). Outras expressões encontradas nos artigos analisados mostram que existem diferentes terminologias para as ações afirmativas em diferentes países. Encontrou-se, por exemplo, as nomenclaturas de políticas compensatórias políticas de acción discriminativa, discriminación positiva o acción positiva. Mesmo utilizando palavras-chaves em 3 idiomas, totalizando 32 possibilidades de combinações para pesquisa, ainda houve uma predominância de textos brasileiros.

O tema das ações afirmativas no ensino superior ainda não é aprofundado de maneira contínua pelos pesquisadores. A grande maioria dos autores explora o tema na sua instituição de estudo ou trabalho -cada um com suas peculiaridades e seu contexto-gerando conclusões que não podem ser generalizáveis. Além disso, uma grande quantidade de artigos críticos e opinativos sem clara base teórica, publicados principalmente antes da publicação da lei também geraram resultados que pouco contribuem para a reflexão sobre o tema. Como relatado, $90 \%$ dos autores publicaram apenas uma vez no tema e muitos escolhem estudar uma única realidade, em ambientes bem conhecidos e de fácil acesso aos dados. Isso não precisaria necessariamente ser uma limitação, se pudesse favorecer o conhecimento regional das ações afirmativas. Porém, até agora, os estudos ficaram esparsos e confinados a realidades específicas, sem diálogos consistentes com outras realidades. Nesse sentido, percebemos que o presente estudo traz como benefício, não somente o panorama do que já foi pesquisado, mas também do que precisa e pode ser estudado.

Como sugestão, pensando no acima exposto, uma pesquisa apenas com os casos encontrados nesta pesquisa, que totalizam 57, abordando os temas de acesso, permanência e eficácia das políticas em cada instituição, para que se possa ter um olhar mais amplo e regionalizado. Outra possibilidade é um estudo integrativo de diferentes instituições que adotaram as ações afirmativas em diferentes estados brasileiros. Pesquisas mais holísticas ou contemplativas de outros aspectos sempre podem contribuir para a compreensão do tema e para a evolução de soluções para novos desafios que as ações afirmativas continuam a gerar.

As ações afirmativas no ensino superior iniciaram há décadas em diversos países e continuam a funcionar até hoje. Não se pode afirmar que isso acontecerá da mesma maneira no Brasil, uma vez que cada país tem seu contexto político, econômico e social. Antes disso, o mais importante é verificar constantemente a eficácia dessas políticas aqui. A política de ações afirmativas poderá deixar de existir quando políticas estruturais que fortaleçam e invistam na educação de base passem a ser executadas. Em geral podemos dizer que a política tem avançado desde seu início, principalmente em relação ao acesso. É preciso avançar em correlação a análise da permanência ou não destes estudantes para que a política cumpra sua finalidade ou se este é o meio mais adequado para essa reparação social. As ações afirmativas de acesso à universidade demonstram o reconhecimento, ou afirmação, das assimetrias sociais em ação, buscando corrigir de diferenças históricas a grupos até então marginalizados ou excluídos. 
doi: http://doi.org/10.15359/ree.24-1.16

URL: http://www.una.ac.cr/educare

CORREO: educare@una.cr

\section{Referências}

As referências marcadas com * indicam os estudos incluídos nas análises qualitativa e quantitativa.

*Abitante, A. L. R. (2017). O impacto da política pública de reserva de vagas sobre o desempenho acadêmico dos alunos em disciplina do curso de arquitetura e urbanismo da Universidade Federal do Rio Grande do Sul. Pensamento \& Realidade, 32(1), 1-15. Recuperado de http:// www.spell.org.br/documentos/ver/45016/o-impacto-da-politica-publica-de-reservade-vagas-sobre-o-desempenho-academico-dos-alunos-em-disciplina-do-curso-dearquitetura-e-urbanismo-da-universidade-federal-do-rio-grande-do-sul/i/pt-br

*Albuquerque, R. de A. F., \& Pedron, C. D. (2015). Os objetivos das ações afirmativas em uma IES Pública Brasileira: a Percepção da Comunidade Acadêmica. Encontro da Associação Nacional de Pós-Graduação e Pesquisa em Administração, 39, Belo Horizonte, MG, Brasil. Recuperado de http://www.anpad.org.br/ anpad/eventos.php?cod evento=1\&cod edicao subsecao $=1198 \&$ cod evento edicao $=78 \&$ cod edicao trabalho $=19360$

*Amaral,W. R., \&Baibich-Faria,T.M. (2012). A presença dos estudantes indígenas nas universidades estaduais do Paraná: trajetórias e pertencimentos. Revista Brasileira de Estudos Pedagógicos, 93(235), 818-835. doi: https://dx.doi.org/10.1590/S2176-66812012000400014

*Andrade, E. de C. (2007). Effects of the brazilian university policy of targeting the poor. Estudos Econômicos (São Paulo), 37(3), 663-683. doi: https://dx.doi.org/10.1590/S0101$\underline{41612007000300008}$

*Andrade, E. de C. (2010). Higher education: free tuition vs. quotas vs. targeted vouchers. Estudos Econômicos (São Paulo), 40(1), 43-66. doi: https://dx.doi.org/10.1590/S0101$\underline{41612010000100002}$

*Aranha, A. V. S., Pena, C. S., \& Ribeiro, S. H. R. (2012). Programas de inclusão na UFMG: o efeito do bônus e do Reuni nos quatro primeiros anos de vigência - um estudo sobre acesso e permanência. Educação em Revista, 28(4), 317-345. doi: https://dx.doi.org/10.1590/S0102$\underline{46982012000400013}$

*Artes, A., \& Ricoldi, A. M. (2015). Acesso de negros no ensino superior: o que mudou entre 2000 e 2010. Cadernos de Pesquisa, 45(158), 858-881. doi: https://dx.doi. org/10.1590/198053143273

*Baeta Neves, C. E. (2014). Enseñanza superior em Brazil y las politicas de inclusión social. Páginas de Educación, 7(2), 152-177. Recuperado de http://www.scielo.edu.uy/scielo. php?script=sci arttext\&pid=S1688-74682014000200008\&lng=es\&tlng=es 
Bardin, L. (2010). Análise de conteúdo (Trad. L. A. Reto, \& A. Pinheiro). Lisboa: Edições 70.

*Barreyro, G. B., \& Costa, F. L. O. (2015). Las políticas de educación superior en Brasil en la primera década del siglo XXI: Algunas evidencias sobre impactos positivos en la equidad. Revista mexicana de investigación educativa, 20(64), 17-46. Recuperado de http://www.scielo.org. $\underline{\mathrm{mx} / \mathrm{scielo} . p h p \text { ?script=sci arttext\&pid=S1405-66662015000100003\&lng=es\&tlng=es }}$

*Barros, V. R. F., Melo, M. C. de O. L., \& Lopes, A. L. M. (2015). O Prouni e a promoção do empoderamento de mulheres: estudo com egressas de uma Instituição de Ensino Superior privada mineira. Encontro da Associação Nacional de Pós-Graduação e Pesquisa em Administração, 39, Belo Horizonte, MG, Brasil. Recuperado de http://www.anpad.org. $\mathrm{br} /$ anpad/eventos.php?cod evento $=1 \&$ cod edicao subsecao $=1198 \&$ cod evento edicao $=78 \&$ cod edicao trabalho $=19621$

*Batista, N. C. (2015). Políticas públicas de ações afirmativas para a Educação Superior: o Conselho Universitário como arena de disputas. Ensaio: Avaliação e Políticas Públicas em Educação, 23(86), 95-128. doi: https://dx.doi.org/10.1590/S0104-40362015000100004

*Bayma, F. (2012). Reflexões sobre a constitucionalidade das cotas raciais em Universidades Públicas no Brasil: referências internacionais e os desafios pós-julgamento das cotas. Ensaio: Avaliação e Políticas Públicas em Educação, 20(75), 325-346. doi: https://dx.doi. org/10.1590/S0104-40362012000200006

*Bevilaqua, C. B. (2015). The institutional life of rules and regulations: ten years of affirmative action policies at the Federal University of Paraná, Brazil. Vibrant: Virtual Brazilian Anthropology, 12(2), 193-232. doi: https://dx.doi.org/10.1590/1809-43412015v12n2p193

*Bezerra, T. O. C., \& Gurgel, C. R. M. (2012). A política pública de cotas em universidades, enquanto instrumento de inclusão social. Pensamento \& Realidade, 27(2), 95-117. Recuperado de $\quad$ http://www.spell.org.br/documentos/ver/43587/a-politica-publica-de-cotas-emuniversidades--enquanto-instrumento-de-inclusao-social/i/pt-br

*Bispo, F. C. da S., \& dos Santos, A. B., Jr. (2013). Uma análise do Programa Universidade para Todos e sua relação com a democratização do acesso ao Ensino Superior e a redução de desigualdades regionais. 37 Encontro da Associação Nacional de Pós-Graduação e Pesquisa em Administração, Rio de Janeiro, RJ, Brasil. Recuperado de http://www.anpad. org.br/ anpad/eventos.php?cod evento $=1 \&$ cod edicao subsecao $=966 \&$ cod evento edicao $=68 \&$ cod edicao trabalho $=15729$

*Brandão, A. A., \& de Marins, M. T. A. (2007). Cotas para negros no Ensino Superior e formas de classificação racial. Educação e Pesquisa, 33(1), 27-45. doi: https://dx.doi.org/10.1590/ $\underline{\text { S1517-97022007000100003 }}$ 
doi: http://doi.org/10.15359/ree.24-1.16

URL: http://www.una.ac.cr/educare

CORREO: educare@una.cr

*Camino, L., Tavares, T. L., Torres, A. R. R., Álvaro, J. L., \& Garrido, A. (2014). Repertórios discursivos de estudantes universitários sobre cotas raciais nas universidades públicas brasileiras. Psicologia \& Sociedade, 26(spe), 117-128. doi: https://dx.doi.org/10.1590/S0102$\underline{71822014000500013}$

*Campos, L. A., \& Feres, Jr., J. (2014). Ação afirmativa, comunitarismo e multiculturalismo: relações necessárias ou contingentes? Revista Brasileira de Ciências Sociais, 29(84), 103118. doi: https://dx.doi.org/10.1590/S0102-69092014000100007

*Campos, L. C., Machado, T. R. B., Miranda, G. J., \& Costa, P. de S. (2017). Social quotas, affirmative actions, and dropout in the Business field: empirical analysis in a Brazilian federal university. Revista Contabilidade e Finanças, 28(73), 27-42. doi: http://dx.doi.org/10.1590/1808$\underline{057 \times 201702590}$

*Casali, A. M. D., \& de Mattos, M. J. V. M. (2015). Análise de estudos e pesquisas sobre o sentido social do programa Universidade para Todos (PROUNI). Ensaio: Avaliação e Políticas Públicas em Educação, 23(88), 681-716. doi: https://dx.doi.org/10.1590/S0104-40362015000300007

*Castro, M. P., Aranda, C., Castro, C., de Torres, H., Lizama, C., \& Williams, J. (2014). Sistematización de la implementación del sistema de ingreso prioritario de equidad educativa (excupo de equidad) en la carrera de Psicología de la Universidad de Chile 2010-2012. Calidad en la educación, 40, 337-353. doi: https://dx.doi.org/10.4067/S0718-45652014000100012

*Cervi, E. U. (2013). Ações afirmativas no vestibular da UFPR entre 2005 a 2012: de política afirmativa racial a política afirmativa de gênero. Revista Brasileira de Ciência Política, 11, 6388. doi: https://dx.doi.org/10.1590/S0103-33522013000200003

*Chávez Achong, J. (2013). Universidad Nacional Agraria La Molina - Perú: Inclusión social y discriminación social. Revista Lusófona de Educação, 24(24), 135-151. Recuperado de https://revistas.ulusofona.pt/index.php/rleducacao/article/view/4181

*Chiroleu, A. (2009). Políticas públicas de inclusión en la educación superior los casos de Argentina y Brasil. Pro-Posições, 20(2), 141-166. doi: https://dx.doi.org/10.1590/S0103$\underline{73072009000200010}$

*Cicalò, A. G. (2008). What Do We Know About Quotas? Data and Considerations About the Implementation of the Quota System in the State University of Rio de Janeiro (UERJ). Universitas Humanística, 65, 261-278. Recuperado de http://www.scielo.org.co/ scielo.php?script=sci arttext\&pid=S0120-48072008000100012\&lng=en\&tlng=en 
*Cohen, L. B., Exner, M. K., \& Gandolfi, P. (2016). Os Resultados da Implementação da Política de Cotas em um Campus Universitário Federal no Interior do Estado de Minas Gerais. 40 Encontro da Associação Nacional de Pós-Graduação e Pesquisa em Administração, Costa do Sauípe, BA, Brasil. Recuperado de http://www.anpad.org.br/ anpad/eventos.php?cod evento $=1 \&$ cod edicao subsecao $=1302 \&$ cod evento edicao $=83 \&$ cod edicao trabalho $=20920$

*Colo, A. (2013). Race and affirmative action: The implementation of quotas for "Black" students in a Brazilian University. Antipoda. Revista de Antropología y Arqueología, 16, 113-133. doi: https://doi.org/10.7440/antipoda16.2013.06

Congreso Nacional, Brasília. (2012). Lei No 12.711, de 29 de agosto de 2012. Dispõe sobre o ingresso nas universidades federais e nas instituições federais de ensino técnico de nível médio e dá outras providências. Recuperado de http://www.planalto.gov.br/ccivil 03/ ato20112014/2012/lei/l12711.htm

Congreso Nacional, Brasília. (2016). Lei No 13.409, de 28 de dezembro de 2016. Altera a Lei $n^{\circ}$ 12.711 , de 29 de agosto de 2012, para dispor sobre a reserva de vagas para pessoas com deficiência nos cursos técnico de nível médio e superior das instituições federais de ensino. Recuperado de http://www.planalto.gov.br/ccivil 03/ ato2015-2018/2016/lei/ L13409.htm

*da Silva, L. P., Dias, L. C. F., \& da Silva, J. S. (2014). Políticas Públicas de Ensino Superior: Fragilidades na Avaliação e Dificuldades para os Seus Beneficiários no Mercado de Trabalho. 6 Encontro de Administração Pública e Governança, Belo Horizonte, MG, Brasil. Recuperado de http://www.anpad.org.br/ anpad/eventos.php?cod evento=6\&cod edicao subsecao $=1106 \&$ cod evento edicao $=74 \&$ cod edicao trabalho $=18059$

*Daflon, V. T., Feres, Jr., J., \& Campos, L. A. (2013). Ações afirmativas raciais no ensino superior público brasileiro: um panorama analítico. Cadernos de Pesquisa, 43(148), 302-327. doi: https://dx.doi.org/10.1590/S0100-15742013000100015

* de Anhaia, B. C. (2012). Políticas públicas e sociais para a equidade: um estudo sobre o programa universidade para todos. Cadernos Gestão Pública e Cidadania, 17(60), 1-19. doi: https:// doi.org/10.12660/cgpc.v17n60.4029

* de Jesus, J. G. (2013). O desafio da convivência: assessoria de diversidade e apoio aos cotistas (2004-2008). Psicologia: Ciência e Profissão, 33(1), 222-233. doi: https://dx.doi.org/10.1590/ $\underline{\mathrm{S} 1414-98932013000100017}$

* de Mello e Souza, A. (2012). Desempenho dos candidatos no vestibular e o sistema de cotas na UERJ. Ensaio: Avaliação e Políticas Públicas em Educação, 20(77), 701-724. doi: https:// dx.doi.org/10.1590/S0104-40362012000400005 
doi: http://doi.org/10.15359/ree.24-1.16

URL: http://www.una.ac.cr/educare

CORREO: educare@una.cr

*de Mendonça, C. M. C., Guerra, L. C. B., Mendonça, A. V. P. de M., de Sousa Neto, M. V. (2015). Políticas de Acesso à Educação Superior e Desempenho de Alunos Bolsistas: o Caso de uma Universidade Privada de Natal/RN. RAUnP - Revista Eletrônica do Mestrado Profissional em Administração da Universidade Potiguar, 7(2), 15-29. Recuperado de http://www.spell.org. br/documentos/ver/37464/politicas-de-acesso-a-educacao-superior-e-desempenho-dealunos-bolsistas--o-caso-de-uma-universidade-privada-de-natal-rn/i/pt-br

*de Oliveira, E. I. I., \& Molina, R. M. K. (2012). A ampliação da base social da educação superior no contexto do Centro Universitário do Leste de Minas Gerais: o caso do ProUni. Revista Brasileira de Estudos Pedagógicos, 93(235), 743-769. doi: https://dx.doi.org/10.1590/S2176$\underline{66812012000400011}$

* de Souza, A. C., \& Teixeira Brandalise, M. Â. (2015). Democratização, justiça social e igualdade na avaliação de uma política afirmativa: com a palavra, os estudantes. Ensaio: Avaliação e Políticas Públicas em Educação, 23(86), 181-212. doi: https://dx.doi.org/10.1590/S010440362015000100007

*de Souza, A. C., \& Teixeira Brandalise, M. Â. (2016). Avaliação da política de cotas da UEPG: desvelando o direito à igualdade e à diferença. Revista da Avaliação da Educação Superior, 21(2), 415-438. doi: https://dx.doi.org/10.1590/S1414-40772016000200006

*do Amaral, D. P., \& de Oliveira, F. B. (2011a). O Prouni e a conclusão do ensino superior: novas trajetórias pessoais e profissionais dos egressos. Ensaio: Avaliação e Políticas Públicas em Educação, 19(73), 861-890. doi: https://dx.doi.org/10.1590/S0104-40362011000500008

* do Amaral, D. P., \& de Oliveira, F. B. (2011 b). O ProUni e a conclusão do ensino superior: questões introdutórias sobre os egressos do programa na zona oeste do Rio de Janeiro. Ensaio: Avaliação e Políticas Públicas em Educação, 19(70), 21-42. doi: https://dx.doi.org/10.1590/ $\underline{\text { S0104-40362011000100003 }}$

* dos Passos, J. C. (2015). Relações raciais, cultura acadêmica e tensionamentos após ações afirmativas. Educação em Revista, 31(2), 155-182. doi: https://dx.doi.org/10.1590/0102$\underline{4698134242}$

*dos Santos, E. F., \& Scopinho, R. A. (2016). Desigualdades Raciais, Mérito e Excelência Acadêmica: Representações Sociais em Disputa. Psicologia: Ciência e Profissão, 36(2), 267-279. doi: https://dx.doi.org/10.1590/1982-3703000532014

*dos Santos, S. A., Cavalleiro, E., Barbosa, M. I. da S., \& Ribeiro, M. (2008). Ações afirmativas: polêmicas e possibilidades sobre igualdade racial e o papel do estado. Revista Estudos Feministas, 16(3), 913-929. doi: https://dx.doi.org/10.1590/S0104-026X2008000300012 
*e Silva, P. B., \& da Silva, P. (2012). Representações sociais de estudantes universitários sobre cotas na universidade. Fractal: Revista de Psicologia, 24(3), 525-542. doi: https://dx.doi. org/10.1590/S1984-02922012000300007

*Espinoza Díaz, O., \& González, L. E. (2012). Políticas de educación superior en Chile desde la perspectiva de la equidad. Sociedad y Economía, 22, 68-94. Recuperado de http://www. scielo.org.co/scielo.php?script=sci arttext\&pid=S1657-63572012000100004\&lng=en\&t| $\underline{\mathrm{ng}=\mathrm{es}}$

*Felicetti, V. L., Cabrera, A. F., \& Costa-Morosini, M. (2014). Aluno ProUni: impacto na instituçao de educação superior e na sociedade. Revista iberoamericana de educación superior, 5(13), 21-39. doi: https://doi.org/10.1016/S2007-2872(14)71951-1

*Felicetti, V. L., \& Costa Morosini, M. (2009). Equidade e iniquidade no ensino superior: uma reflexão. Ensaio: Avaliação e Políticas Públicas em Educação, 17(62), 9-24. doi: https://dx.doi. org/10.1590/S0104-40362009000100002

*Felicetti, V. L., \& Fossatti, P. (2014). Alunos ProUni e não ProUni nos cursos de licenciatura: evasão em foco. Educar em Revista, 51, 265-282. doi: https://dx.doi.org/10.1590/S010440602014000100016

*Feres Jr., J., \& Daflon, V. T. (2015). Ação afirmativa na Índia e no Brasil: um estudo sobre a retórica acadêmica. Sociologias, 17(40), 92-123. doi: https://dx.doi.org/10.1590/15174522$\underline{017004003}$

*Ferreiras, R. F., \& Mattos, R. M. (2007). O afro-brasileiro e o debate sobre o sistema de cotas: um enfoque psicossocial. Psicologia: Ciência e Profissão, 27(1), 46-63. doi: https://dx.doi. org/10.1590/S1414-98932007000100005

*Fontele, T. L. L., \& Crisóstomo, V. L. (2016). PROUNI - pontos controversos sob a análise de alunos bolsistas. Avaliação: Revista da Avaliação da Educação Superior, 21(3), 739-766. doi: https:// dx.doi.org/10.1590/S1414-40772016000300005

*Griner, A., Gomes, A. C. C., Sampaio, L. M. B., \& de Souza, S. K. C. (2013). Políticas de cotas: desempenho acadêmico e determinantes de acesso à Universidade Federal do Rio Grande do Norte. Revista Ciências Administrativas, 19(1), 166-185. Recuperado de http:// www.spell.org.br/documentos/ver/38414/affirmative-actions--academic-performanceand-determinants-of-access-to-federal-university-of-rio-grande-do-norte/i/en

*Griner, A., Sampaio, L. M. B., \& Sampaio, R. M. B. (2015). A política afirmativa "Argumento de Inclusão" como forma de acesso à universidade pública: o caso da Universidade Federal do Rio Grande do Norte. Revista de Administração Pública, 49(5), 1291-1317. doi: https:// dx.doi.org/10.1590/0034-7612123593 
doi: http://doi.org/10.15359/ree.24-1.16

URL: http://www.una.ac.cr/educare

CORREO: educare@una.cr

*Guarnieri, F. V., \& Melo-Silva, L. L. (2007). Ações afirmativas na educação superior: rumos da discussão nos últimos cinco anos. Psicologia \& Sociedade, 19(2), 70-78. doi: https://dx.doi. org/10.1590/S0102-71822007000200010

*Guarnieri, F. V., \& Melo-Silva, L. L. (2010). Perspectivas de estudantes em situação de vestibular sobre as cotas universitárias. Psicologia \& Sociedade, 22(3), 486-498. doi: https://dx.doi. org/10.1590/S0102-71822010000300009

*Haas, C. M., \& Linhares, M. (2012). Políticas públicas de ações afirmativas para ingresso na educação superior se justificam no Brasil? Revista Brasileira de Estudos Pedagógicos, 93(235), 836-863. doi: https://dx.doi.org/10.1590/S2176-66812012000400015

*Heringer, R., \& Honorato, G. de S. (2015). Elementos para uma análise dos estudantes cotistas e bolsistas no curso de pedagogia da UFRJ. Caderno $C R H, 28(74), 341-348$. doi: https:// dx.doi.org/10.1590/S0103-49792015000200007

*lizuka, E. S. (2016). A Política de Cotas nas Universidades Brasileiras: Como ela Chegou à Agenda de Políticas Públicas? Amazônia, Organizações e Sustentabilidade, 5(2), 41-58. Recuperado de http://revistas.unama.br/index.php/aos/article/view/445

Instituto Brasileiro de Geografia e Estatística (IBGE). (2016). Síntese de indicadores sociais: uma análise das condições de vida da população brasileira. Río de Janeiro: IBGE. Recuperado de https://biblioteca.ibge.gov.br/visualizacao/livros/liv98965.pdf

Jaccoud, L., \& Beghin, N. (2002). Desigualdades raciais no Brasil: um balanço da intervenção governamental. Brasilia: ipea. Recuperado de http://www.ipea.gov.br/portal/index. php?option $=$ com content $\&$ view $=$ article\&id $=5442$

*Kern, M. C. L., \& Ziliotto, D. M. (2011). Universidade pública e inclusão social: as cotas para autodeclarados negros na Universidade Federal do Rio Grande do Sul. Cadernos Gestão Pública e Cidadania, 16(59), 1-19. doi: https://doi.org/10.12660/cgpc.v16n59.3752

*Leite, J. L. (2011). Política de cotas no Brasil: política social? Revista Katálysis, 14(1), 23-31. doi: https://dx.doi.org/10.1590/S1414-49802011000100003

*Lima, M. E. O., Neves, P. S. da C., \& e Silva, P. B. (2014). A implantação de cotas na universidade: paternalismo e ameaça à posição dos grupos dominantes. Revista Brasileira de Educação, 19(56), 141-163. doi: https://dx.doi.org/10.1590/S1413-24782014000100008

*Lloyd, M. (2016). Una década de políticas de acción afirmativa en la educación superior brasileña: impactos, alcances y futuro. Revista de la educación superior, 45(178), 17-29. doi: https://dx.doi.org/10.1016/j.resu.2016.02.002 
*Magnoni, M. S. (2016). Lei de Cotas e a mídia brasileira: o que diria Lima Barreto? Estudos Avançados, 30(87), 299-312. doi: https://dx.doi.org/10.1590/S0103-40142016.30870017

* Mata Carnevali, M. G. (2008). India:Educación con reservas. Educere, 12(42), 635-643. Recuperado de https://www.redalyc.org/articulo.oa?id=35614569025

*Matos, M. dos S., Pimenta, S. G., de Almeida, M. I., \& Oliveira, M. A. de C. (2012). O impacto do Programa de Inclusão Social da Universidade de São Paulo no acesso de estudantes de escola pública ao ensino superior público gratuito. Revista Brasileira de Estudos Pedagógicos, 93(235), 720-742. doi: https://dx.doi.org/10.1590/S2176-66812012000400010

*Mendes Junior, A. A. F. (2014). Uma análise da progressão dos alunos cotistas sob a primeira ação afirmativa brasileira no ensino superior: o caso da Universidade do Estado do Rio de Janeiro. Ensaio: Avaliação e Políticas Públicas em Educação, 22(82), 31-56. doi: https:// dx.doi.org/10.1590/S0104-40362014000100003

*Menin, M. S. de S., Shimizu, A. de M., da Silva, D. J., Cioldi, F. L., \& Buschini, F. (2008). Representações de estudantes universitários sobre alunos cotistas: confronto de valores. Educação e Pesquisa, 34(2), 255-272. doi: https://dx.doi.org/10.1590/S1517-97022008000200004

*Mongim, A. B. (2016). Itinerários de escolarização e mediações subjacentes: a experiência de discentes beneficiários do Prouni. Ensaio:Avaliação e Políticas Públicas em Educação, 24(93), 804-823. doi: https://dx.doi.org/10.1590/S0104-40362016000400002

*Moya, C. (2011). Equidad en el acceso a la educación superior: los "cupos de equidad" en la Facultad de Ciencias Sociales de la Universidad de Chile. Calidad en la educación, 35, 255275. doi: https://dx.doi.org/10.4067/S0718-45652011000200011

*Nery, M. da P., \& Costa, L. F. (2009a). Afetividade entre estudantes e sistema de cotas para negros. Paidéia, 19(43), 257-266. doi: https://dx.doi.org/10.1590/S0103-863X2009000200014

*Nery, M. da P., \& Costa, L. F. (2009b). Política afirmativa racial: polêmicas e processos de identidade do cotista universitário. Psico-USF, 14(2), 211-220. doi: https://dx.doi.org/10.1590/S1413$\underline{82712009000200010}$

*Neves, P. S. C., Faro, A., \& Schmitz, H. (2016). As ações afirmativas na Universidade Federal de Sergipe e o reconhecimento social: a face oculta das avaliações. Ensaio: Avaliação e Políticas Públicas em Educação, 24(90), 127-160. doi: https://dx.doi.org/10.1590/S0104$\underline{40362016000100006}$

*Neves, P. S. C., \& Lima, M. E. O. (2007). Percepções de justiça social e atitudes de estudantes pré-vestibulandos e universitários sobre as cotas para negros e pardos nas universidades públicas. Revista Brasileira de Educação, 12(34), 17-38. doi: https://dx.doi.org/10.1590/ $\underline{\text { S1413-24782007000100003 }}$ 
doi: http://doi.org/10.15359/ree.24-1.16

URL: http://www.una.ac.cr/educare

CORREO: educare@una.cr

*Nunes, M. L. F., \& Neira, M. G. (2014). Processos de inclusão excludente presentes no ensino superior privado. Educação \& Realidade, 39(4), 1209-1228. doi: https://dx.doi.org/10.1590/ $\underline{\mathrm{S} 2175-62362014000400014}$

*Osorio, R. G. (2009). Classe, raça e acesso ao ensino superior no Brasil. Cadernos de Pesquisa, 39(138), 867-880. doi: https://dx.doi.org/10.1590/S0100-15742009000300009

*Paixão, R. B., Pereira, M. A. M., \& dos Santos, L. C. (2015). Desempenho Acadêmico dos Alunos Declarados Cotistas e Não Cotistas do Curso de Bacharelado em Administração da Universidade Federal da Bahia. 5 Encontro de Ensino e Pesquisa em Administração e Contabilidade, Salvador, BA, Brasil. Recuperado de http://www.anpad.org. $\mathrm{br} / \sim a n p a d / e v e n t o s . p h p ? c o d$ evento $=18 \& \mathrm{cod}$ edicao subsecao $=1208 \& \mathrm{cod}$ evento edicao $=79 \&$ cod edicao trabalho $=20373$

*Passos, G. de O., \& Gomes, M. B. (2014). A instituição da reserva de vagas na universidade pública brasileira: os meandros da formulação de uma política. Ensaio: Avaliação $e$ Políticas Públicas em Educação, 22(85), 1091-1114. doi: https://dx.doi.org/10.1590/S0104$\underline{40362014000400010}$

*Paulo, E. S. (2010). Preliminary studies on affirmative action in a Brazilian university. Revista de Administração Mackenzie, 11(3), 27-45. doi: https://doi.org/10.1590/S1678$\underline{69712010000300004}$

*Pedroza Flores, R., \& Villalobos Monroy, G. (2009). Políticas compensatorias para la equidad de la educación superior en Argentina, Bolivia y Venezuela. Revista de la Educación Superior, 38(152), 33-48. Recuperado de http://www.scielo.org.mx/scielo.php?script=sci arttext\&pid=S0185-27602009000400003\&lng=es\&tlng=es

*Peixoto, A. de L. A., Ribeiro, E. M. B. de A., Bastos, A. V. B., \& Ramalho, M. C. K. (2016). Cotas e desempenho acadêmico na UFBA: um estudo a partir dos coeficientes de rendimento. Avaliação: Revista da Avaliação da Educação Superior, 21(2), 569-592. doi: https://dx.doi. org/10.1590/S1414-40772016000200013

* Picanço, F. (2015). Juventude por cor e renda no acesso ao ensino superior: somando desvantagens, multiplicando desigualdades? Revista Brasileira de Ciências Sociais, 30(88), 145-181. doi: https://dx.doi.org/10.17666/3088145-179/2015

*Piotto, D. C., \& Nogueira, M. A. (2016). Incluindo quem? Um exame de indicadores socioeconômicos do Programa de Inclusão Social da USP. Educação e Pesquisa, 42(3), 625 649. doi: https://dx.doi.org/10.1590/S1517-9702201609134896

${ }^{*}$ Queiroz, Z. C. L. S., Miranda, G. J., Tavares, M., \& de Freitas, S. C. (2015). A lei de cotas na perspectiva do desempenho acadêmico na Universidade Federal de Uberlândia. Revista Brasileira de Estudos Pedagógicos, 96(243), 299-320. doi: https://dx.doi.org/10.1590/S2176$6681 / 339112863$ 
*Ristoff, D. (2014). O novo perfil do campus brasileiro: uma análise do perfil socioeconômico do estudante de graduação. Avaliação: Revista da Avaliação da Educação Superior, 19(3), 723 747. doi: https://dx.doi.org/10.1590/S1414-40772014000300010

*Rossetto, C. B. de S., \& Gonçalves, F. de O. (2015). Equidade na Educação Superior no Brasil: Uma Análise Multinomial das Políticas Públicas de Acesso. Dados, 58(3), 791-824. doi: https:// dx.doi.org/10.1590/00115258201559

*Santos, C. T. (2012). Ações afirmativas no ensino superior: análise do perfil socioeconômico e da experiência universitária de bolsistas do ProUni na PUC-Rio. Revista Brasileira de Estudos Pedagógicos, 93(235),770-790.doi:https://dx.doi.org/10.1590/S2176-66812012000400012

*Santos, H., de Souza, M. G., \& Sasaki, K. (2013). O subproduto social advindo das cotas raciais na educação superior do Brasil. Revista Brasileira de Estudos Pedagógicos, 94(237), 542-563. doi: https://dx.doi.org/10.1590/S2176-66812013000200010

*Saraiva, L. A. S., \& Nunes, A. de S. (2011). A efetividade de programas sociais de acesso à educação superior: o caso do ProUni. Revista de Administração Pública, 45(4), 941-964. doi: https://dx.doi.org/10.1590/S0034-76122011000400003

*Serafim, N. K. P., \& Gomes, R. C. de A. (2015). Meritocracia e o Sistema de Cotas nas Universidades Brasileiras: um Estudo de Caso com Estudantes da Universidade Federal Rural do SemiÁrido (UFERSA). 39 Encontro da Associação Nacional de Pós-Graduação e Pesquisa em Administração, Belo Horizonte, MG, Brasil. Recuperado de http://www.anpad.org. $\mathrm{br} /$ anpad/eventos.php?cod evento $=1 \& \mathrm{cod}$ edicao subsecao $=1198 \& \mathrm{cod}$ evento edicao $=78 \&$ cod edicao trabalho $=19575$

*Silva, T. D. (2016). Ação Afirmativa para Ingresso de Negros no Ensino Superior: a Formação da Agenda Governamental segundo Atores-Chave. 40 Encontro da Associação Nacional de Pós-Graduação e Pesquisa em Administração, Costa do Sauípe, BA, Brasil. Recuperado de $\quad$ http://www.anpad.org.br/ anpad/eventos.php?cod evento=1\&cod edicao subsecao $=1302 \&$ cod evento edicao $=83 \&$ cod edicao trabalho $=20921$

*Sito, L. (2014). Disputas e diálogos em torno do conceito de "ações afirmativas" para o ensino superior no Brasil. Universitas Humanística, 77, 251-273. doi: https://doi.org/10.11144/ Javeriana.UH77.ddet

Souza, A. de M. e. (2012). Desempenho dos candidatos no vestibular e o sistema de cotas na UERJ. Ensaio: Avaliação e Políticas Públicas em Educação, 20(77), 701-724. doi: https:// dx.doi.org/10.1590/S0104-40362012000400005

Souza, J. (2017). A elite do atraso: da escravidão à lava jato. Rio de Janeiro: Leya. 
doi: http://doi.org/10.15359/ree.24-1.16

URL: http://www.una.ac.cr/educare

CORREO: educare@una.cr

*Souza, M. R. de A., \& Menezes, M. (2014). Programa Universidade para Todos (PROUNI): quem ganha o quê, como e quando? Ensaio: Avaliação e Políticas Públicas em Educação, 22(84), 609-633. doi: https://dx.doi.org/10.1590/S0104-40362014000300003

*Trevisol, J.V., \& Nierotka, R. L. (2016). Os jovens das camadas populares na universidade pública: acesso e permanência. Revista Katálysis, 19(1), 22-32. doi: https://dx.doi.org/10.1590/1414$\underline{49802016.00100003}$

*Turgeon, M., Chaves, B. S., \& Wives, W. W. (2014). Políticas de ação afirmativa e o experimento de listas: o caso das cotas raciais na universidade brasileira. Opinião Pública, 20(3), 363-376. doi: https://dx.doi.org/10.1590/1807-01912014203363

Urrútia, G. y Bonfill, X. (2010). Declaración PRISMA: Una propuesta para mejorar la publicación de revisiones sistemáticas y metaanálisis. Medicina Clínica, 135(11), 505-506. doi: 10.1016/j. medcli.2010.01.015

*Velloso, J. (2009). Cotistas e não-cotistas: rendimento de alunos da Universidade de Brasília. Cadernos de Pesquisa, 39(137), 621-644. doi: https://dx.doi.org/10.1590/S010015742009000200014

*Wainer, J., \& Melguizo, T. (2017). Políticas de inclusão no ensino superior: avaliação do desempenho dos alunos baseado no Enade de 2012 a 2014. Educação e Pesquisa, 44, 1-15. doi: https://dx.doi.org/10.1590/s1517-9702201612162807

*Weller, W., \& Silveira, M. (2008). Ações afirmativas no sistema educacional: trajetórias de jovens negras da universidade de Brasília. Revista Estudos Feministas, 16(3), 931-947. doi: https:// dx.doi.org/10.1590/S0104-026X2008000300013

*Winther, J. M., \& Golgher, A. B. (2010). Uma investigação sobre a aplicação de bônus adicional como política de ação afirmativa na Universidade Federal de Minas Gerais (UFMG). Revista Brasileira de Estudos de População, 27(2), 333-359. doi: https://dx.doi.org/10.1590/S0102$\underline{30982010000200007}$

Zoltowski, A. P. C., Costa, A. B., Teixeira, M. A. P., \& Koller, S. H. (2014). Qualidade metodológica das revisões sistemáticas em periódicos de psicologia brasileiros. Psicologia: Teoria e pesquisa, 30(1), 97-104. doi: http://dx.doi.org/10.1590/S0102-37722014000100012 